\title{
José Joaquín Fernández de Lizardi oder die Erfindung einer Leserschaft in Hispanoamerika
}

Sehen wir uns aber nun nicht länger die europäischen Projektionen mit ihren erfundenen Figuren, ihren bons sauvages und ihren imaginierten Landschaften an, die in Richtung der amerikanischen Hemisphäre entworfen wurden, sondern versuchen wir, all jene Veränderungen zu begreifen, die sich mit Blick auf eine in Entstehung begriffene Literatur im künftigen Lateinamerika zu Beginn des 19. Jahrhunderts abzeichneten! Denn es ist spannend zu beobachten, auf welche Weise sich in der Neuen Welt und in den sich langsam herausbildenden protonationalen Staatsgebilden des amerikanischen Kontinents zusammen mit einem neuen Lesepublikum eine Literatur herauskristallisierte, die auf die Bedürfnisse und Notwendigkeiten dieser Leserschaft einzugehen suchte.

In seinem vielbeachteten Essay über die Entwicklung des lateinamerikanischen Romans hat der uruguayische Kritiker und Literaturtheoretiker Angel Rama die These vertreten, José Joaquín Fernández de Lizardis Roman El Periquillo Sarniento sei von einer ihm zugrunde liegenden ,archaischen“ Struktur geprägt. Hören wir uns seine Argumente gegen jenen Text einmal an, der als der erste hispanoamerikanische, von einem Hispanoamerikaner in Hispanoamerika verfasste Roman gilt:

Der Pícaro, den Lizardi erfindet, ist nicht nur ein thematischer, sondern auch ein formaler Archaismus. Er restauriert die ursprüngliche Bedingtheit des Romans als Waffe im Kampf um die Zerstörung einer etablierten Ordnung, wobei er die klassische (und im übrigen einzige von der Ordnung zugelassene) List des unverantwortlichen Sprechens eines gesellschaftlich Geächteten anwendet: des Enterbten oder Verrückten, des Blindenführers oder Quijote. ${ }^{1}$

Der Vorwurf des Archaismus lastet - dies verdeutlicht die Argumentation des uruguayischen Literarhistorikers - schwer auf Fernández de Lizardis erstem, 1816 in unvollständiger Form erstmals veröffentlichtem Roman, der bekanntlich Anspruch darauf erheben darf, am Beginn von dessen Entwicklung im künftigen Lateinamerika zu stehen. Denn die Verknüpfung zwischen Herausbildung des Romans und soziopolitischer Entwicklung der unabhängig gewordenen lateinamerikanischen Nationen, die hier geradezu selbstverständlich erfolgt, wird von Angel Rama in der narrativen Modellierung einer Urschuld präsentiert. Denn der renommierte uruguayische Kritiker attackiert die Verstrickung des lateinamerikanischen

1 Rama, Angel: La formación de la novela latinoamericana. In (ders.): La novela en América Latina. Panoramas 1920-1980. Montevideo - Xalapa: Fundación Angel Rama - Universidad Veracruzana 1986, S. 21. 
Romans mit den Zielen und Absichten einer einzigen gesellschaftlichen Klasse, die als Sprachrohr für ihre Forderungen allein die Figur des spanischen pícaro, des Enterbten oder Verrückten, akzeptiert habe. Roman und Nation scheinen in Lateinamerika $a b$ initio aus der Perspektive Ramas vom selben Virus befallen: vom Virus ihrer Funktionalisierung durch Normen und Werte des aufstrebenden Bürgertums.

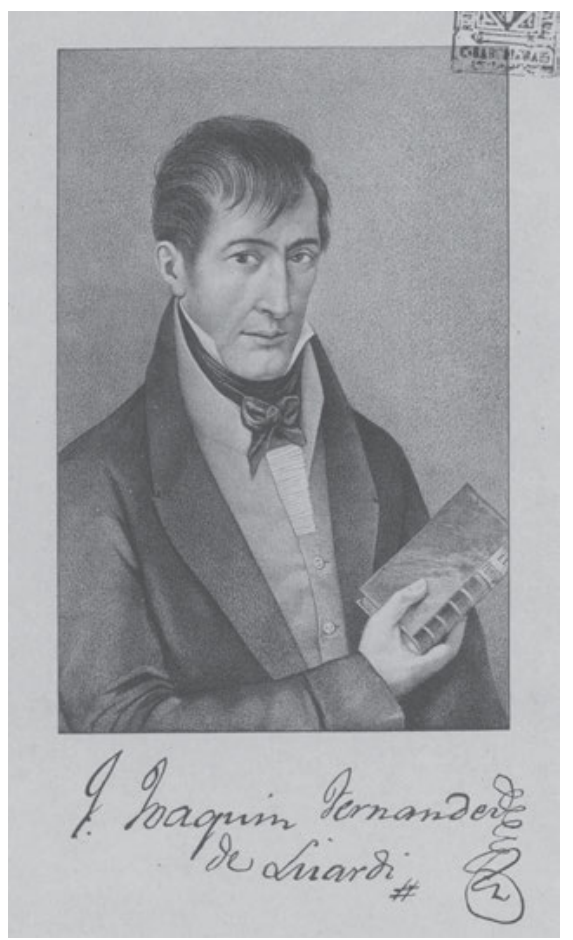

Abb. 87: José Joaquín Fernández de Lizardi (Mexiko-Stadt, damals Neuspanien, 1776 ebenda, 1827).

Es ist in der Tat verlockend, vor dem Hintergrund einer nachweisbaren relativen Gleichzeitigkeit die literarische mit der politischen Formgebung auf dem amerikanischen Kontinent in Verbindung zu bringen, ja Romanschöpfung und Nationbildung miteinander zu parallelisieren. Dies kann, wie etwa bei Rama, in negativ eingefärbter Weise erfolgen. Doch eine solche Vorgehensweise kann auch deutlich positive Vorzeichen erhalten wie bei Noël Salomon, wo Fernández de Lizardis Roman in einem vielzitierten Aufsatz schlicht als Roman der mexikanischen Unabhängigkeit, als „la novela de la independencia mexicana““2 bezeichnet

2 Salomon, Noël: La crítica del sistema colonial de la Nueva España en „El Periquillo Sarniento“. In: Cuadernos Americanos (México) XXI, 138 (1965), p. 179. 


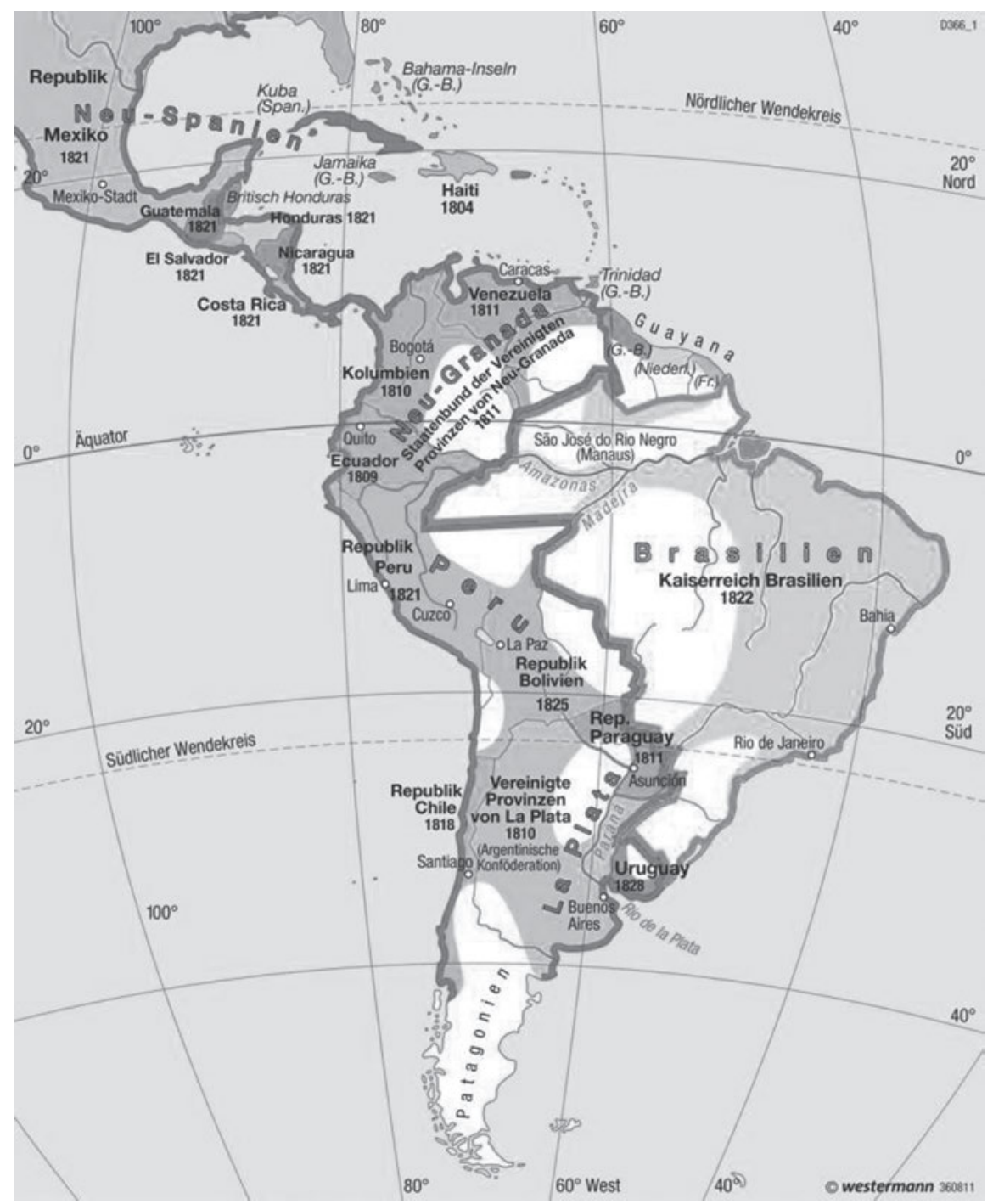

Abb. 88: „Mittel- und Südamerika: Nationalstaaten um 1825 (Ende der Befreiungskriege)“.

wurde. Die Übereinstimmung zwischen beiden Herangehensweisen ist beeindruckend, verweist die literarische Gestaltung doch in jedem Falle direkt und unvermittelt auf eine zugrunde gelegte gesellschaftliche Entwicklung zurück.

In beiden Fällen wäre die relative Gleichzeitigkeit der Ereignisse nicht kontingent, sondern epistemologisch wirksam im selben generierenden Kontext $\mathrm{zu}$ verorten. Romanentwicklung und gesellschaftliche Entwicklung stünden in 


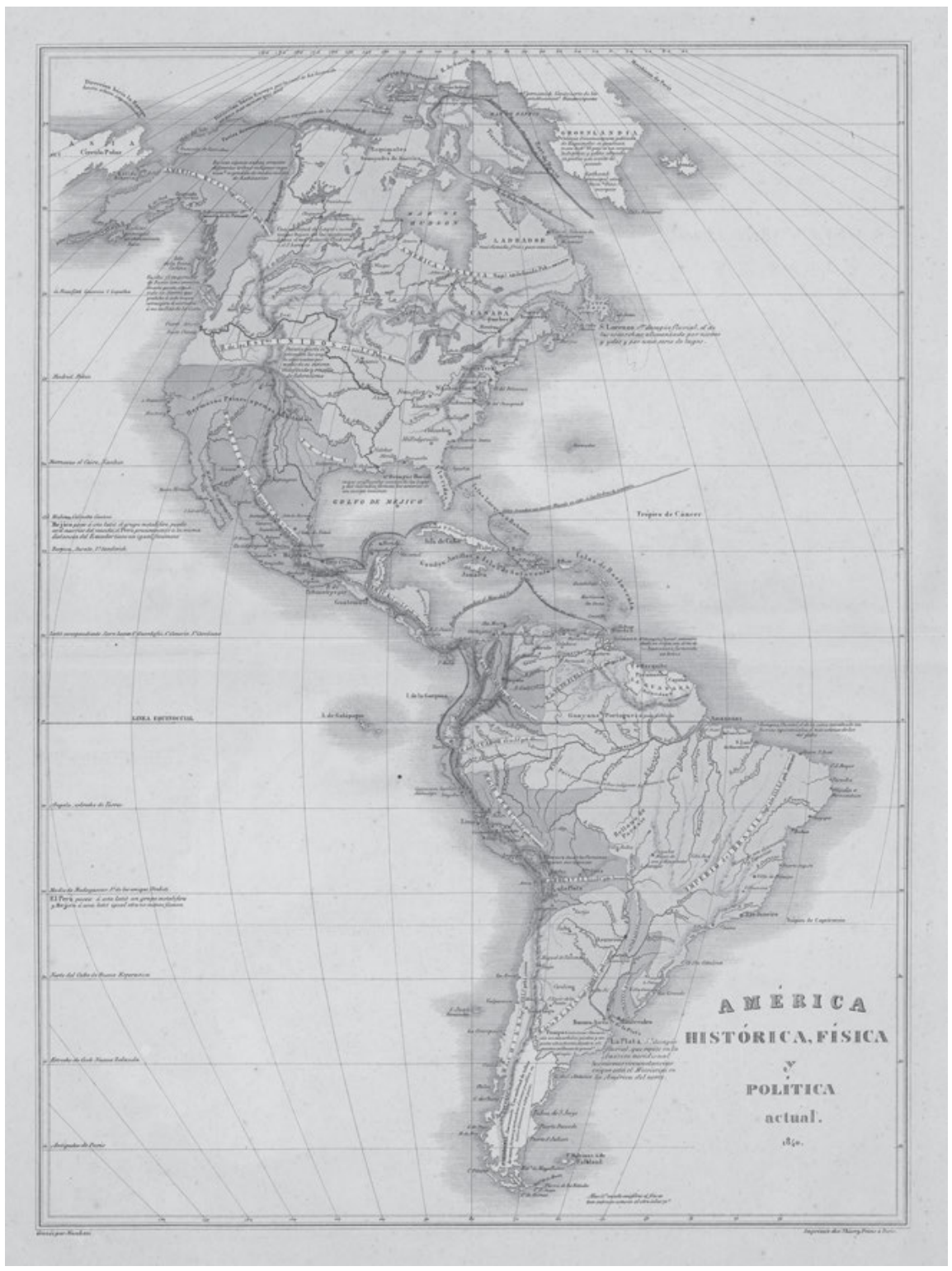

Abb. 89: „Historische, physische und politische Karte von Amerika“, Karte von Agustin Codazzi, 1840.

einem unmittelbaren Zusammenhang und wären direkt aneinander gekoppelt. Führten wir diesen Gedanken weiter, so könnten wir den von Rama behaupteten „Archaismus“ auf thematischer wie formaler Ebene als Paradoxon (und zugleich 
als Aporie) deuten und für die Entwicklungsgeschichte des Romans in Lateinamerika fruchtbar machen. Denn was wäre zeitgemäßer und aktueller innerhalb einer anachronistisch im kolonialspanischen System verwurzelten neuspanischen Gesellschaft als eben jene von Spanien ererbte Figur des literarischen Schelms, des pícaro?

Doch so einfach liegen die Dinge keineswegs! Denn der als so anachronistisch gebrandmarkte Schelmenroman - der im Übrigen bis in unsere Tage weder in Amerika noch in Europa etwas von seiner kritischen Wirkkraft und ästhetischen Potenz verloren hat - erwiese sich so als eben jene Form, welche die literarästhethisch und literarhistorisch überzeugendste Antwort auf die spezifische Situation Neuspaniens, des künftigen Mexico, am Ausgang seiner langen Kolonialgeschichte zu geben vermag. Und in der Tat soll El Periquillo Sarniento - soweit dürfen wir den nachfolgenden Ausführungen etwas vorgreifen - als innerhalb neuer gesellschaftlicher, politischer und historischer Kontexte resemantisierte und refunktionalisierte literarische Form verstanden werden, durch welche Alte und Neue Welt in einen schöpferischen Polylog miteinander verwickelt werden. Dies gäbe dem großen Roman von Fernández de Lizardi ein ganz außerordentliches Gewicht und eine Bedeutung, die weit über das strikt Literarästhetische hinausreicht.

Aus einer solchen Perspektive betrachtet, wäre dann die Beziehung zwischen Roman und Nation weder eine zu geißelnde Verstrickung noch eine zu begrüßende zukunftsträchtige Befreiung. Sie erwiese sich als ein dynamisches und dynamisierendes Element, das zweifellos gattungskonstitutiv verstanden werden könnte, ohne doch die gänzlich anders modellierten Räume von literarischer Äußerung und nationaler Genese als analog strukturierte Aspekte ein und desselben geschichtlichen Prozesses $\mathrm{zu}$ verstehen und unvermittelt aufeinander $\mathrm{zu}$ beziehen. Es ginge um die Einschaltung komplexer dynamischer Vermittlungen, die ein literarisches Artefakt mit einem bestimmten gesellschaftlichen System und dessen Entwicklung verbinden würde. Der Ausgangspunkt hierfür wäre ein durchaus literatursoziologischer. ${ }^{3}$

Eine derart veränderte Perspektivik setzte uns in die Lage, die Offenheit der Lizardi'schen Romankonstruktion für die Zukunft zurückzugewinnen und von Fernández de Lizardi verwendete narrative Gattungsspezifika der novela picaresca wie auch der Utopie als Beziehungsgeflechte eines polylogischen Schreibens zu verstehen, das weder als „,archaisch“ noch als „,anachronistisch“ fehlgedeutet werden sollte. Die große ästhetische Spannbreite des Lizardi’schen

3 Vgl. etwa Köhler, Erich: Vermittlungen. Romanistische Beiträge zu einer historisch-soziologischen Literaturwissenschaft. München: Fink 1976. 
Romanprojekts wäre damit wieder zurückgewonnen - und zugleich dessen Zukunftsoffenheit innerhalb eines literaturgeschichtlichen Prozesses, welcher das 19. und 20. Jahrhundert der lateinamerikanischen Literaturen höchst erfolgreich queren sollte.

Doch es gibt noch ein weiteres Hindernis, das sich vor unserem Verständnis von Lizardis Roman auftürmt. Denn wir müssen unsere Lektüre mit Hilfe dieser Überlegungen zugleich von einem zweiten, die Rezeptionsgeschichte von Fernández de Lizardis El Periquillo Sarniento bis heute belastenden Vorwurf befreien, demzufolge diesem Text eine monologische und dogmatische Grundstruktur eigne. Den vielleicht drastischsten Beleg für diese noch immer anhaltende Kritik liefert uns der mexikanische Kritiker Carlos González Peña, der 1910 nicht zögerte, im intellektuellen Kontext des Ateneo - und vor dem Hintergrund einer weiteren sich anbahnenden Revolution in Mexico -, Fernández de Lizardis Roman als „die abgeschmackteste Predigt, die unsere Nationalliteratur erinnert“ zu bezeichnen. ${ }^{4}$ Wie kam Lizardis Roman zu dieser so negativen Wertschätzung?

Zweifellos sind es die zahlreichen diskursiven Einschübe und Digressionen und nicht so sehr (wie noch Rama meinte) die Figur des pícaro selbst, die bis in unsere Gegenwart verschiedensten Formen adäquater Rezeption im Wege stehen. Ja, der Periquillo Sarniento hat für die Lektüre, hat für unsere leserische Annäherung etwas recht Sperriges! Doch sollten wir uns davor hüten, ein „Moralisieren“ mit Monologisieren und die komplexe Struktur dieses Romans mit einer Predigt gleichzusetzen, der selbstverständlich stets etwas Dogmatisches anhaftet. Die nachfolgende Analyse soll vielmehr zeigen, in welch subtiler und komplexer Weise polylogische Strukturen in Fernández de Lizardis Schreiben eingewoben sind und wie sehr es uns die Bewusstmachung dieser Strukturierungen erlaubt, jenseits dieser beiden auf diesem texto fundador lastenden Vorwürfe die historische Tiefenschärfe wie auch die ästhetische Leistung von Fernández de Lizardis Romanerstling herauszuarbeiten.

Damit ist nicht allein der Wert des Periquillo Sarniento als zeitgeschichtliches Dokument oder gar als nationales Monument gemeint. Fraglos ist dieser Roman ein Fenster in der Zeit, eine „ventana abierta hacia el pasado“; ${ }^{5}$ doch dürfen wir darüber - ganz im Derrida'schen Sinne ${ }^{6}$ - nicht den kunstvoll verfertigten Rahmen vergessen, der den Raum dieses ,ersten im eigentlichen Sinne hispa-

4 González Peña, Carlos: El Pensador Mexicano y su tiempo. In: Conferencias del Ateneo de la Juventud. México, D.F.: Imprenta Lacaud 1910, S. 102; zitiert nach Skirius, John: Fernández de Lizardi y Cervantes. In: Nueva Revista de Filología Hispánica (México) XXXI, 2 (1982), S. 259: „el más abominable sermón de que las letras nacionales tienen memoria“.

5 Ebda., S. 258.

6 Derrida, Jacques: La vérité en peinture. Paris: Flammarion 1978. 
noamerikanischen Romans“"7 in der Zeit konfiguriert. Nähern wir uns diesem Text aus der Leserperspektive an, aus jener Perspektive also, die zunächst von außen kommend jenen paratextuellen Apparat überfliegt oder wahrnimmt, der einen literarischen Text über unterschiedlichste Schwellen in Beziehung zur Welt außerhalb des Textes setzt! Denn gerade die Paratextualität, die Vorworte, Nachworte, Glossen oder Titel und Zwischentitel können uns sehr viel über die Leserschaft sagen, die mit diesen Schwellentexten angesprochen werden sollte.

Dabei müssen historische Lektüren berücksichtigt werden, welche ihrerseits zu diversen Editionen und Herausgeberschaften führten. Denn der Vorwurf predigtartigen Monologisierens und moralisierender Langatmigkeit hat in der Editionsgeschichte wohlmeinende Herausgeber auf den Plan gerufen und zu verschiedenen ,Lösungen' dieser Problematik angeregt. Beispielhaft hierfür - sieht man von der gängigen Praxis gekürzter Ausgaben einmal ab - ist eine mexikanische Edition von 1942, die ihrem Leser den Schnelldurchgang durch den Periquillo Sarniento mit Hilfe einer Kursivsetzung all jener Passagen zu erleichtern versuchte, die man der Rubrik der „Digression“ zuordnen konnte. ${ }^{8}$ Deutlich radikaler und pragmatischer noch ging jene englischsprachige Ausgabe vor, die - im selben Jahr 1942 erschienen - auf derlei „Beiwerk“ verzichten zu können glaubte und sich auf das vermeintlich Essentielle beschränkte. ${ }^{9}$ Eine derartige Vorgehensweise hat innerhalb der Editions- und Übersetzungsgeschichte des europäischen Schelmenromans berühmte Vorbilder, strich doch kein Geringerer als Alain-René Lesage in seiner Neuübersetzung von Mateo Alemáns Guzmán de Alfarache kurzerhand all jene Passagen heraus, die er für überflüssiges Moralisieren (,moralités superflues“) hielt. ${ }^{10}$ Gerade im Schelmenroman hatten sogenannte ,leserfreundliche“ philologische Eingriffe mithin Tradition, glaubte man doch, ganz einfach das ,Überflüssige‘ vom ,wirklich Wichtigen' fein säuberlich trennen zu können.

Nicht viel besser erging es den zahlreichen Paratexten, die Fernández de Lizardi seinem Roman in Form von Vorworten, Widmungen, Motti, Anmerkungen oder herausgeberischen Intermezzi an die Seite gab, wurden doch auch sie in einer Vielzahl von Ausgaben offenkundig aus Platzgründen ,ausgespart‘,

7 Iñigo Madrigal, Luis: José Joaquín Fernández de Lizardi. In (ders., Hg.): Historia de la literatura hispanoamericana. Bd. II: Del neoclasicismo al modernismo. Madrid: Cátedra 1987, S. 143: „primera novela propiamente hispanoamericana“.

8 Vgl. Vogeley, Nancy: Defining the „Colonial Reader“: „El Periquillo Sarniento“. In: PMLA (New York) CII, 5 (1987), S. 798.

9 Vgl. Skirius, John: Fernández de Lizardi y Cervantes, S. 258.

10 Vgl. hierzu u. a. die schöne Einführung von Micó, José María: Introducción. In: Alemán, Mateo: Guzmán de Alfarache. Bd. 1. Madrid: Cátedra ${ }^{31994, ~ S . ~} 40$. 
begrenzt oder schlicht gänzlich gestrichen. Das Fortlassen dieser Textelemente aber bewirkt einen völlig veränderten Zugang der Leserschaft zum gesamten Roman und löscht die Spuren einer subtilen Arbeit am Text aus, die nicht nur für das weite Untersuchungsfeld der von Fernández de Lizardi bewusst eingesetzten literarischen Verfahren, sondern auch für die hier analysierte Entstehung einer Leserschaft in den spanischen Kolonien im Übergang zur Unabhängigkeit sowie die Problematik des Zusammenhangs zwischen Roman und Nation im Spannungsfeld der hispanoamerikanisch-europäischen Literaturbeziehungen von größter Bedeutung ist. Für diese Beziehungen ist selbstverständlich die Verbindung mit der Leserschaft und zur Lektüre überhaupt zentral.

Vorworte oder Widmungen sind von großer Textrelevanz und eine wahre Proliferation paratextueller Elemente stellt ein Wesensmerkmal dieses ersten Romans Fernández de Lizardis dar. Dies betrifft insbesondere die Vorworte, die unserem Roman in vielfacher Weise beigegeben sind, präsentiert sich dieser Text seinen Leserinnen und Lesern doch mit einem „Prólogo, dedicatoria y advertencia a los lectores“, gefolgt von einem „Prólogo de Periquillo Sarniento“ sowie den „Advertencias generales a los lectores“, also allgemeinen Hinweisen für die Leserschaft.

Es geht auf dieser paratextuellen Ebene folglich im Wesentlichen um die Vorworte als Figuren von Leserkonstellationen sowie als Gebrauchsanweisungen für die „richtige“ Lektüre. Darüber hinaus erheben im weiteren Fortgang des Romans ein „Prólogo en traje de cuento“ sowie die „Notas del Pensador“ erneut Anspruch auf die Aufmerksamkeit der Leserschaft.

Diese anonyme Leserschaft wird gleich zu Beginn des ersten Vorworts direkt als „Señores míos“ briefformelhaft angesprochen, eine Referenz, die in der Gattungsgeschichte eine direkte Verbindung zum anonymen Lazarillo de Tormes herstellt, mit dem El Periquillo Sarniento im Übrigen auch das paratextuelle Element des Titeldiminutivs verbindet. Verweisen gleich die ersten paratextuellen Markierungen mithin auf die spanische Gattungstradition, die gleichsam in autobiographischer Variation durch die Verwendung eines Zitats von Torres Villarroel als Motto des gesamten Textes die Kontinuität autobiographischer Schreibformen paratextuell in unseren Roman einblendet, so ist die Wendung an die Leser doch gänzlich verschieden von Lazarillos Anrede von „Vuestra Merced“, jener rätselhaften Figur, der schon immer das Interesse und die Neugier der LazarilloForschung galt. ${ }^{11}$

11 Beispielhaft für die in der Forschung gerne gestellte Frage ist die Studie von Abrams, Fred: To Whom was the Anonymous „Lazarillo de Tormes“ dedicated? In: Romance Notes VIII (1966-67), S. 273-277. 
Denn dieses Modell eines Schreibens im Auftrag einer höhergestellten Persönlichkeit wird schon in (und zwischen) den ersten Zeilen dieses Vorwortes transgrediert. Nicht umsonst verknüpft dieser kurze Text die Funktionen von „prólogo“, „dedicatoria“ und „advertencias“, also von Vorwort, Widmung und Leserhinweisen miteinander.

MEINE HERREN: Eines jener Dinge, die mir bei der Geburt von LEBEN DES PERIQUILLO SARNIENTO Schwierigkeiten bereiteten, bestand darin, Personen auszuwählen, denen ich es zueignen konnte, denn ich habe unendlich viele Werke gesehen, von hohen wie von niederen Verdiensten, die zu Beginn mit derlei Widmungen geschmückt waren.

Solcher Vorsatz oder solch fortgesetzte Gewohnheit ließ mich glauben, dass etwas Gutes daran sei, denn alle Autoren versuchten, ihre Mäzene oder Patrone auszuwählen, denen sie ihre Arbeiten zueignen konnten, in dem festen Glauben, dass solches Tun ihnen Gewinn bescherte.

Ich bestärkte mich noch mehr in dieser Vorstellung, als ich in einem alten Büchlein las, dass es welche gab, die mit einem Subjekt paktierten, ihm das Buch zuzueignen, soundsoviel dafür erhielten: und dass es einen anderen gab, der sein Werk einem Potentaten widmete, um es sodann einem ganz anderen Namen zu konsekrieren; der berühmte englische Historiker Thomas Fuller teilte seine Werke in viele Bände auf, und für jeden Band suchte er sich einen anderen Magnaten zur Zueignung; andere haben sich ihre Produktionen selbst gewidmet, und andere schließlich haben sich davon überzeugt, dass der Drucker ihrer Werke sie ihnen zueigne. ${ }^{12}$

So also beginnt der Text von José Joaquín Fernández de Lizardis sicherlich berühmtestem Roman. Gleich zu Beginn des Textes weicht El Periquillo Sarniento von den Normen und Selbstverständlichkeiten des damaligen kolonialen „Literaturbetriebes“ ab. An die Stelle der dedicatoria selbst treten Reflexionen über die Sitte der Widmung, an die Stelle einer direkten Kommunikation und Ansprache an Auftraggeber beziehungsweise Mäzene tritt in der Folge ein Gespräch mit einem Freund, genauer noch: Der Dialog mit dem Freund situiert sich innerhalb der durch die Eröffnungsformel initiierten schriftlichen Kommunikationssituation. Damit gelingt es Fernández de Lizardi, dem Paratext von Beginn an jene Struktur zu geben, welche sich vereinfachend als Ineinanderschachtelung verschiedener Kommunikationssituationen und Kommunikationsebenen beschreiben lässt, und dabei sowohl auf Formen der Mündlichkeit als auch der Schriftlichkeit zurückgreift. Grundlage hierfür ist die direkte Ansprache, der Dialog, der von Anfang an dazu dient, eine Idee in ihrer Ausgestaltung vorzuführen. Der lesende Leser wird von Beginn an zum mitdenkenden, mitwirkenden, aktiven Lesepublikum.

12 Fernández de Lizardi, José Joaquín: El Periquillo Sarniento. Prólogo de Jefferson Rea Spell. Mexico: Editorial Porrúa 1992, S. 1. 
Der Gedanke, die schwierige „Geburt“ dieses Textes im Lichte seiner Abweichung von vorgegebenen literarischen Regeln und Normen zum Thema des Prologs zu machen, ist indes hintergründiger, als es auf den ersten Blick scheinen will. Denn das Frage- und Antwortspiel mit dem Freund blendet sogleich die soziale Situation des Schriftstellers, die materiellen Bedingungen des Literaturbetriebs wie etwa Druckkosten und Vertriebsmöglichkeiten, vor allem aber auch die nicht mehr nur individuelle Schwierigkeit ein, welche die schriftstellerischen Aktivitäten aller in Amerika Schreibenden betrifft: die grundlegende Problematik, einen Adressaten für die eigenen Werke zu finden. Damit aber ist die Frage nach der Leserschaft, nach den konkreten Leserinnen und Lesern und nicht zuletzt auch nach den Käuferinnen und Käufern derartiger Romane, wie Fernández de Lizardi sie vorlegt, gestellt.

Kein nationaler literarischer Raum, kein Mäzen, kein „Vuestra Merced“ ist Partner in diesem Dialog, sondern ein kollektiver Adressat, jene „Señores míos“, die dem kolonialspanischen und nicht dem metropolitanen spanischen Raum zugehören. Der paratextuelle Raum gibt dieser spezifischen kolonialen (und zumindest perspektivisch einer unmittelbar postkolonialen) Situation konkreten Ausdruck:

\footnotetext{
-Ja, mein Freund-, sagte ich ihm, - und dies ist eine der größten Schwierigkeiten, welche die amerikanischen Talente gehabt haben und noch haben werden, um - wie sie es eigentlich sollten - auf der literarischen Bühne zu glänzen. Die hohen Kosten, die man im Königreich für den Druck der umfangreicheren Werke veranschlagen muss, schrecken viele davon ab, zumal wenn man bedenkt, dass sie das Risiko eingehen, nicht nur den Preis für ihre Mühen nicht zu erhalten, sondern sogar ihr Geld zu verlieren, so dass viele Köstlichkeiten unveröffentlicht im Bücherschrank verbleiben, welche nützlich für ihr Lesepublikum wären und ihren Autoren Ehre machen würden. Dieses Ungemach bewirkt, dass es hier keinerlei Export von keinerlei Werken gibt [...].13
}

Die amerikanischen Autoren befinden sich folglich in einer Zwickmühle, die ihr Schreiben und mehr noch ihr Publizieren extrem behindert. Sie müssten Gelder investieren, über die sie nicht verfügen, um - etwa auch in Übersee - ein Lesepublikum zu erreichen, das für sie aber vorerst unerreichbar bleibt, da es für sie auch keine Mäzene und Förderer in den Kolonien gibt. Es gilt also, so könnten wir folgern, eine eigene amerikanische Leserschaft zu erfinden. Und an eben diese Aufgabe machte sich José Joaquín Fernández de Lizardi.

Der Verfasser des Periquillo Sarniento war ein guter Rechner. Doch wir können uns die im weiteren Verlauf dieser Passage ausgeführte genaue Kalkulation der Kosten für Herstellung, Verschiffung und Verkauf des hier vorgestellten Werkes

13 Ebd., S. 2. 
sparen: Für potentielle Käufer in Spanien käme in jedem Falle dieses Buch zu teuer. Für den in Amerika Schreibenden sind das spanische Publikum und damit das teatro literario, die literarische Bühne und der spanische Literaturbetrieb schlechthin unerreichbar.

Damit ergeben sich, wie der Prolog es andeutet, für Fernández de Lizardi wie für alle in Neuspanien schreibenden Autoren letztlich zwei Möglichkeiten: entweder das Verstummen aufgrund des zu hohen finanziellen Risikos oder die Erschließung neuer Leserschichten im kolonialspanischen Bereich. Das Risiko der hohen Kosten für den Druck seiner Schriften ging Fernández de Lizardi ganz bewusst ein. So bleibt der hispanoamerikanische Schriftsteller auf sein Lesepublikum in Amerika verwiesen. El Periquillo Sarniento trägt die Spuren dieser bewussten und dem Leser bewusstgemachten Entscheidung: Das intendierte (und auf absehbare Zeit einzig erreichbare) Lesepublikum des Romans lebt in den spanischen Kolonien Amerikas. Wer dieses Lesepublikum erreichen will, muss zu ihm sprechen! Denn die Lektüre dieses Publikums allein kann den Schriftsteller vor dem wirtschaftlichen Ruin retten.

Eine eingehende Analyse des Romans macht deutlich, dass dieses amerikanische Lesepublikum auch der implizite Leser ist, für den viele Latinismen, nicht aber die zahlreichen Mexikanismen übersetzt werden. ${ }^{14}$ Dass der reale Leser, an den sich der reale Autor Fernández de Lizardi mit einer Auflage von etwa fünfhundert Exemplaren wandte, diesem Vorhaben entsprach und die verschiedenen Lieferungen des pikaresken Erzählwerkes kaufte, wäre durch rezeptionsund lesesoziologische Untersuchungen erst noch zu belegen. Doch dürfte José Joaquín Fernández de Lizardis Strategie aufgegangen sein, kann er doch, der sich gegen Ende seines Lebens selbst als öffentlicher Schriftsteller, als „escritor público“ ${ }^{15}$ bezeichnete, als der wohl erste Berufsschriftsteller nicht nur Neuspaniens, sondern der hispanoamerikanischen Literaturen in ihrer Gesamtheit gelten. Mit anderen Worten: Seine Rechnung, sein genaues Kalkül, ging auf.

Vor diesem Hintergrund verwundert es nicht, dass das innerhalb der novela picaresca stets zentral behandelte Thema des Geldes nicht erst auf Ebene der histoire, sondern bereits in der paratextuell inszenierten Dialogsituation mit einem Freund (,amigo“) eingeführt wird. Mit Hilfe dieses Kunstgriffs wird die finanziell stets ungesicherte Situation des pícaro mit jener des Schriftstellers korreliert,

14 Vgl. hierzu auch Cros, Edmond: Estructura testamentaria y discurso reformista en el „Periquillo Sarniento“ (México, principios del siglo XIX). In (ders.): Ideosemas y Morfogénesis del Texto. Literaturas española e hispanoamericana. Frankfurt am Main: Vervuert 1992, S. 124.

15 Vgl. hierzu ausführlich Franco, Jean: La heterogeneidad peligrosa: Escritura y control social en vísperas de la independencia mexicana. In: Hispamérica (Gaithersburg) XII, 34-35 (1983), insbes. S. 12ff. 
der ähnlich wie der Protagonist des Schelmenromans ständig auf der Suche nach seinem Platz in der Gesellschaft ist. Die Problematik des Berufsschriftstellers verwandelt damit den Paratext zu einem Bestandteil jenes teatro literario, jener literarischen Bühne, die es in Spanisch-Amerika erst noch zu schaffen galt.

Im Dialog der Freunde präsentiert sich uns eine Literatur, die ihre Adressaten, ihren eigenen Raum sucht und bis zum Erscheinen der ersten Lieferungen auch noch nicht gefunden hat. An diesem Punkt ist die interne Kommunikationssituation mit der externen Kommunikationssituation des Paratextes verbunden und zugleich in ihrer textinternen Modellierung auf die textexterne, ,reale Kommunikationssituation zugeschnitten. Diese Überlappung beider Ebenen, gleichsam jene des pícaro und jene des realen Fernández de Lizardi, macht einen Teil des großen Reizes dieses Romanwerks aus. Dass hiermit auch durchaus intendierte Identifikationsprozesse verbunden waren, versteht sich von selbst.

Wir konstatieren also aus der Perspektive unserer Vorlesung: Ein Roman sucht seine Leser, und zwar dringend! Doch geht es nicht um irgendeinen Text und irgendwelche Leser: Bereits die ersten beiden Seiten des Periquillo Sarniento zeigen, dass es sich bei dem ersten von einem Hispanoamerikaner in Hispanoamerika verfassten Roman um ein kulturelles Produkt handelt, das sich auf dem Markt symbolischer Güter an Leserinnen und Leser in Hispanoamerika wendet und in Konkurrenz ebenso $\mathrm{zu}$ anderen Druckerzeugnissen neuspanischer und nicht-neuspanischer Provenienz wie auch zu weiteren kulturellen Erzeugnissen oder „Luxusgütern“16 tritt.

Als Publizist und Herausgeber des Pensador Mexicano hatte Fernández de Lizardi zuvor die Möglichkeiten, aber auch die Grenzen jenes diskursiven Raumes ${ }^{17}$ erprobt, der sich nur kurzfristig auch in den spanischen Kolonien Amerikas im Gefolge der Verfassung von Cádiz vergrößert hatte. Doch das Handwerk des Schriftstellers war in den spanischen Kolonien risikoreich. Die Verbüßung einer mehrmonatigen Gefängnisstrafe hatte Fernández de Lizardi aufgezeigt, wie nachhaltig sich Staat und Kirche gegen direkte Angriffe zu wehren wussten. Zugleich zeigte ihm diese Erfahrung aber auch, wie sehr die Repräsentanten der Macht derartige Angriffe aber auch zu fürchten hatten, insoweit sich ein Publikum für journalistische Schriften herausgebildet hatte, das gesellschaftskritischen Ansichten offen gegenüberstand. Das Überwechseln von vorherrschend diktionalen $\mathrm{zu}$ vorherrschend fiktionalen Schreibformen, für das El Periquillo

16 Im Gespräch mit dem Freund werden etwa die enormen Aufwendungen der Adligen für Kutschen, Tänze, für das Glücksspiel und andere Zerstreuungen genannt; vgl. ebda., S. 2.

17 Vgl. hierzu auch die Überlegungen von Mora Escalante, Sonia Marta: Le picaresque dans la construction du roman hispano-américain: le cas du „Periquillo“. In: Etudes littéraires (Québec) XXVI, 3 (1993-94), S. 85. 
Sarniento beispielhaft steht, kommt einer erneuten Erprobung der Chancen und der Tragfähigkeit des prekären Marktes für Druckerzeugnisse gleich. Die Situation ist paradox: Fast schiene es, als ob sich ein Roman seinen Markt selbst erzeugen müsste und dies zum Thema seiner eigenen Schöpfung macht. Das Überleben dieser Schöppfung selbst ist aber wiederum vom Markt abhängig.

Doch sind Roman wie angepeilte Leserschaft gewiss keine creatio ex nihilo. Werfen wir daher einen kurzen Blick auf die Vorgeschichte! Seit Ende des 18. Jahrhunderts hatten in verschiedenen urbanen Räumen des spanischen Kolonialreichs in Amerika Periodika einen eigenen, wenn auch noch reduzierten Leserkreis geschaffen, der die Grundlage für die Ausbildung eines nationalen literarischen Marktes in den Kolonien selbst schuf. Eine ebenso nachträgliche wie nachdrückliche Vernetzung dieser verschiedenen nationalen Räume sollte übrigens erst gegen Ende des 19. Jahrhunderts insbesondere mit den Zeitschriften der hispanoamerikanischen Modernisten erfolgen. Sie erst schufen die Grundlage für jenen Aufstieg der Literaturen Lateinamerikas, der im 20. Jahrhundert etwa zum bekannten Phänomen des Boom führte. ${ }^{18}$ Wir befinden uns mit José Joaquín Fernández de Lizardi folglich in einem Schlüsselmoment der Sattelzeit dieser weltliterarischen Entfaltung der künftigen Literaturen Lateinamerikas.

Auch in Neuspanien hatte sich ein gewiss prekärer öffentlicher Raum für Periodika (mit seiner Leserschaft) herausgebildet, wie ihn nach den frühen Zeitschriften der zweiten Hälfte des 18. Jahrhunderts insbesondere der Diario de México zu Beginn des 19. Jahrhunderts nutzte und ausgestaltete. Diesem sich erst langsam findenden Stamm einer Leserschaft weiß sich Fernández de Lizardi verbunden. Ihr signalisiert er auch durch die paratextuelle und romaninterne Nennung des „Pensador Mexicano“, dass er hier - sozusagen vor den Toren der traditionellen ciudad letrada des Vizekönigreichs Neuspanien ${ }^{19}$ - das direkt ansprechbare Publikum vermutet. $^{20}$

Eine solche Vorgehensweise deutet bereits der ursprüngliche Titel des Werkes an: Vida de Periquillo Sarniento, escrita por él para sus hijos, y publicada para los que la quieran leer, por D.J.F. de L. autor del periódico titulado El Pensador Mexicano. Denn innerhalb des bestenfalls embrionär vorhandenen neuspa-

18 Vgl. zum „Boom“ der Literaturen Lateinamerikas und ihrer Rezeption in Europa Müller, Gesine: Die Boom-Autoren heute: García Márquez, Fuentes, Vargas Llosa, Donoso und der Abschied von den großen identitätsstiftenden Entwürfen. Frankfurt am Main: Vervuert 2004; sowie (dies.): Del pueblo al público o la Revolución cubana revis(it)ada por parte de los autores del boom. In: Gremels, Andrea / Spiller, Roland (Hg.): Cuba: la Revolución revis(it)ada. Tübigen: Narr Francke Attempto Verlag 2010, S. 139-150.

19 Vgl. hierzu Rama, Angel: La ciudad letrada. Hanover: Ediciones del Norte 1984, S. 59.

20 Vgl. auch Vogeley, Nancy: Defining the „Colonial Reader“, S. 792. 
nischen Marktes für novohispanische literarische Produkte konnte er als Herausgeber des nach Lockerung der Zensurbestimmungen 1812 begründeten und bis 1814 fortgesetzten El Pensador Mexicano darauf hoffen, durch die Bekanntheit seines Namens einen bestimmten Leserkreis insbesondere innerhalb der kreolischen Leserschaft zu erreichen. Diese Stamm-Leserschaft galt es nun also auszuweiten ...

Analog zur doppelten Kommunikationssituation des ersten Prologs wird damit bereits im ursprünglichen Titel - und damit ebenfalls auf der paratextuellen Ebene - eine Kommunikation auf zwei verschiedenen Ebenen angedeutet: textintern zwischen Periquillo Sarniento und seinen Söhnen, textextern zwischen jenen anonymen Lesern, die dieses Buch „lesen mögen“, und dem Verfasser des Pensador Mexicano, der sogleich den Roman in Beziehung zur journalistischen Produktion Fernández de Lizardis setzt. Dies war gewiss ein kluger Schachzug! Ziel des neuspanischen Autors musste es daher sein, möglichst viele Leserinnen und Leser dazu zu bringen, sein Buch lesen zu wollen und mehr noch den in einzelnen Lieferungen oder entregas gelieferten Roman käuflich zu erwerben. Auch diese Form der Fokussierung einer Leserschaft ist eine wesentliche Aufgabe der paratextuellen Ausstattung des Periquillo Sarniento, die nicht übersehen werden darf. Es handelt sich um einen Roman, der seine Leser erfinden und finden muss, um überhaupt existieren zu können und die ersten Lieferungen $\mathrm{zu}$ überstehen.

Es ist bei José Joaquín Fernández de Lizardi beeindruckend, wie das geschärfte Bewusstsein für die Bedingungen des eigenen Denkens, Schreibens und Publizierens in Neuspanien dieses Schreiben zugleich in das europäisch-amerikanische Spannungsfeld integriert. Spanien, unerreichbar für neuspanische Druckerzeugnisse und zugleich Monopolist der Buchimporte des kolonialspanischen Raumes, wird einem spanischsprachigen Amerika gegenübergestellt, dessen Fähigkeiten sträflich vernachlässigt werden und im kolonialen Kontext brachliegen.

Innerhalb dieses spanisch-hispanoamerikanischen Spannungsfeldes aber muss sich das Schreiben in Amerika notwendig situieren und bewegen. Damit wird die größere Einheit deutlich, innerhalb derer die im Vorwort agierenden Figuren - das Ich, der Freund wie auch das angesprochene Publikum - handeln: das (spanischsprachige) Amerika. Auf kreative Weise wird in diesem „ersten frei lateinamerikanischen Roman“ ${ }^{21}$ auch der hispanoamerikanische Raum als

21 Rama, Angel: La ciudad letrada, S. 59: „primera franca novela latinoamericana. “ Zur Stellung des Romans im Gesamtwerk vgl. auch Meyer-Minnemann, Klaus: Apropiaciones de realidad en las novelas de José Joaquín Fernández de Lizardi. In: Dill, Hans-Otto / Gründler, Carola / Gunia, Inke / Meyer-Minnemann, Klaus (Hg.): Apropiaciones de realidad en la novela hispanoamericana de los siglos XIX y XX. Frankfurt am Main - Madrid: Vervuert 1994, S. 47-61. 
eigener Raum des Lesens und Schreibens skizziert und vor allem präsentiert. Eine protonationale Leserschaft ist in Entstehung begriffen - ganz so, wie sich Neuspanien auf dem Weg zur mexikanischen Nationbildung befand.

Doch damit sind die Probleme im entstehenden literarischen Feld der spanischen Kolonie noch keineswegs ausgeräumt. Denn die Begrenzungen des amerikanischen beziehungsweise neuspanischen Schriftstellers sind offensichtlich und nicht einfach $\mathrm{zu}$ beseitigen. Seine ökonomische Situation ist auf Grund seines fehlenden materiellen, und des immer noch prekären Wertes seines symbolischen Kapitals auf einem erst embrionär vorhandenen literarischen Markt für eigene, das heißt amerikanische Erzeugnisse stets gefährdet. Dies macht bereits innerhalb des reichhaltigen paratextuellen Apparats der Dialog mit dem Freunde deutlich:

- Ach, Du Bruder meiner Seele! Du hast bei mir eine Enttäuschung ausgelöst, aber zugleich auch eine große Trauer. Ja, Du hast mir die Augen geöffnet, indem Du mir eine Reihe von Wahrheiten an den Kopf geworfen hast, welche leider unwiderlegbar sind; und das Schlimmste an alledem ist, dass ich zu guter Letzt meine Arbeit verliere; denn obwohl ich begrenzt bin und aus diesen Gründen auch von mir keine erhabenen Dinge zu erwarten sind, sondern eher recht Bescheidenes, Triviales, glaube mir, so hat mich dieses kleine Werk doch Arbeit gekostet, und dies umso mehr, als ich ein Stümper bin und ohne Werkzeug gearbeitet habe. ${ }^{22}$

Es mag zunächst überraschen: Wir haben es hier paratextuell mit dem Selbstporträt des literarischen Autors als eines unerfahrenen Stümpers zu tun. Wenn sich das Ich in dieser Passage auch als wenig kenntnisreichen und keineswegs zu sublimen Dingen fähig darstellt - Wesensmerkmale eines literarischen Autors, wie sie auch das noch zu besprechende Selbstporträt gegen Ende des Romans plakatiert -, so erhebt sie doch begründete Ansprüche auf Entlohnung der Bemühungen dieses Ich.

Der in dieser Argumentation ins Zentrum gestellte und von der Gesellschaft zu goutierende Wert ist gerade für den chambón, für den Stümper, den wir als Autodidakten mit beschränkten Kenntnissen verstehen können, der seiner Arbeit. Verbunden mit dem Streben nach Verbesserung der Gesellschaft handelt es sich bei der Arbeit zugleich um jenen Wert, der auf der Ebene der histoire narrativ und auf der Ebene der Kommentare und Digressionen diskursiv ständig als Prinzip in Szene gesetzt wird, an dem sich eine künftige, eine bessere Gesellschaft zu orientieren habe. Der Fokus des gesamten Romans ist zweifellos prospektiv: Stets geht es um eine Gesellschaft, die in der Zukunft eine gerechtere und ausgeglichenere Gemeinschaft sein müsse und sein werde. Schriftstellerische Arbeit tritt hier an

22 Fernández de Lizardi, José Joaquín: El Periquillo Sarniento, S. 3. 
die Stelle von Schmeicheleien und Huldigungen innerhalb einer Ständegesellschaft, die den Autor nur in der Figur des Mäzens, dem alle Ehre zu erweisen ist, unterstützt.

Worin aber besteht diese schriftstellerische Arbeit genau? Die Widmung des Werkes an ein keineswegs erlauchtes, sondern bunt zusammengewürfeltes Publikum - eine Widmung, die mitunter den Tatbestand der Publikumsbeschimpfung erfüllt - gibt uns auf diese Frage eine erste Antwort. Ebenso die Publikumsbeschimpfung wie der gesamte paratextuelle Apparat stehen in einem dialogischen intertextuellen Verhältnis zu den umfangreichen Paratexten des Guzmán de Alfarache, $\mathrm{zu}$ denen gemäß der literarischen Gepflogenheiten der Zeit nicht nur eine Widmung nebst Herrscherlob, sondern auch ein vilipendio del vulgo zählte. José Joaquín Fernández de Lizardi hat in einer geistreichen Volte die Funktionen der bei Mateo Alemán voneinander getrennten Widmungen und Wendungen an einen Mäzen, an das niedere Volk und an den discreto lector miteinander verbunden und zugleich dem niederen Volk und allgemeinen Publikum ebenso Widmung wie Leserorientierung zugedacht. Er erweist sich damit als ein überaus geschickter Schriftsteller und keineswegs als ein Stümper, der es sehr wohl versteht, die unterschiedlichsten Traditionslinien für sein eigenes Werk kreativ fruchtbar zu machen.

Die Rekontextualisierung und Resemantisierung konventioneller Schreibformen verweist auf Verfahren eines dialogischen und in letzter Instanz polylogischen, in mehreren Logiken zugleich agierenden Schreibens, das sich der Notwendigkeit spielerischer Aneignung und interkultureller Übersetzung überaus bewusst ist. Denn diese Arbeit besteht zuallererst in der Suche nach einem neuen Publikum und dem Versuch, dieses neue Publikum nicht nur an das eigene Schreiben, an die Literatur heranzuführen, sondern gleichsam in dieses Schreiben zu verwickeln, Leser und Autor - und sei es nur auf der Ebene der Fiktion gemeinsam im besten Sinne zu kompromittieren. Dies aber ist eine fundamentale, um eine neue Grundlage für ein neues Literatursystem ringende Arbeit, wie Fernández de Lizardi sehr wohl wusste:

Was soll ich von Euren ruhmreichen Heldentaten berichten, außer dass sie in der Tat unwägbar und unwissbar sind?

Was werde ich von Euren Titeln und von Euren Abschriften sagen, außer dass Ihr nicht nur Du und Sie seid und sein könnt, sondern hochwichtig, hochberühmt, hochverehrenswert und dass Ihr Exzellenzen seid, was weiß ich noch alles, Eminenzen, Serenissimi, Hoheiten und Majestäten? Und eingedenk Eurer Tugenden, wer wird denn je genügen, um Eure Grandezza und Würde zu bewerten? Wer wollte würdig Eure Verdienste hervorheben? Wer vermöchte es, Eure Tugend wie Eure Wissenschaften auch nur zu umreißen? Und wer vermag es zuletzt, die hochmögenden Namen Eurer hochberühmten Häuser aufzuzählen noch all die Adler, Tiger, Löwen, Hunde und Katzen, welche Eure Adelswappen bevölkern? 
Ich weiß sehr wohl, dass Ihr von einem Undankbaren abstammt und verwandtschaftliche Beziehungen besitzt zu brudermörderischen Kains, zu götzenverehrenden Nabucos, zu prostituierten Dalilas, zu heilsverfluchenden Baltasaren, zu den verfluchten Canes, zu den verräterischen Judas, zu den perfiden Sinonen, zu den räuberischen Cacos, zu den ketzerischen Arrios und zu einer Vielzahl von Pícaros und Pícaras, welche in derselben Welt wie wir gelebt haben und noch leben.

Ich weiß, dass wohl einige von Euch Plebejer, Indianer, Mulatten, Neger, lasterhafte Dummköpfe und Bekloppte sind.

Aber all dies will ich Euch nicht in Erinnerung rufen, versuche ich doch, Euer Wohlwollen und Eure Zuneigung zu erreichen gegenüber jenem Werk, das ich Euch zueigne [...]. ${ }^{23}$

Welch eine wunderbare Publikumsbeschimpfung, die selbst noch einen Peter Handke hinter sich lässt! Welch eine Auflistung an Auszeichnungen, die ein angestrebtes Lesepublikum charakterisieren, das sich in Teilen zumindest bereits herauszuschälen begann! Fürwahr ein ausgeklügeltes Lob für eine Leserschaft, die sich direkt vom Autor angesprochen fühlen musste. Doch Vorsicht: Im Kontext einer Gesellschaft, in der nur eine kleine Minderheit des Lesens kundig war, darf dieses Publikumsporträt nicht - wie dies freilich immer wieder gerne geschah wörtlich genommen und mit dem von Fernández de Lizardi tatsächlich erreichten realen Publikum gleichgesetzt werden! Denn die Leserschaft des neuspanischen Autors bestand gewiss nicht vorrangig aus Arbeitern, Indianern und Schwarzen, die allesamt nicht zur ciudad letrada, zur Stadt der Gebildeten, gehörten.

Freilich leben all diese Arbeiter, Plebejer und Spitzbuben, Indianer, Schwarze und Mulatten in eben jener Welt, in der sich das nosotros, das Wir des in den Plural wechselnden und mit „El Pensador“ signierenden Ich-Erzählers ansiedelt. Perspektivisch mag sich damit durchaus ein künftiges Lesepublikum abzeichnen; das reale oder auch nur intendierte Publikum stellen die hier Angesprochenen keinesfalls dar. Kein Zweifel: Das nosotros wendet sich an eine alphabetisierte urbane, kreolische Schicht, die seit dem Ausgang des 18. Jahrhunderts zur Trägerschicht der novohispanischen Aufklärung wurde.

Dabei handelt es sich um eine neue Leserschaft, die sich außerhalb der ciudad letrada und deren Konsekrationsmechanismen, außerhalb der Aulen und Hörsäle, ${ }^{24}$ in einem buchstäblich doppelten Wortsinne gebildet hat. Die Vielfalt an Regionalismen und schicht- wie vermeintlich rassenspezifischen Sprachmerkmalen, die in den Periquillo Sarniento Eingang fanden, darf uns nicht darüber hinwegtäuschen, dass es eine Ebene von Sprache und Stil gibt, welche Autor und intendierter Leserschaft gemeinsam sind. Es handelt sich dabei weder um die Sprache der kulturellen Elite (der traditionellen ciudad letrada) noch um jene der

23 Fernández de Lizardi, José Joaquín: El Periquillo Sarniento, S. 3f.

24 Vgl. hierzu auch Franco, Jean: La heterogeneidad peligrosa, S. 13. 
urbanen Halbwelt. So erklärt der fiktive Herausgeber „Lizardi“ in Hinblick auf die von Pedro Sarmiento gewählte Stilhöhe:

Er schrieb sein Leben nieder in einem Stil, der weder kriecherisch noch aufgeblasen ist; er hütet sich davor, den Gelehrten zu geben, es ist ein umgänglicher und familiärer Stil, wie wir ihn alle gemeinhin benutzen, in dem wir uns verstehen und mit Leichtigkeit zu verstehen geben. ${ }^{25}$

Diese kurze Passage ist im Rahmen unserer Vorlesung für eine Untersuchung der Leserschaft des Periquillo Sarniento von erheblicher Bedeutung. Denn das angesprochene „Wir“ dieser Passage verbindet fiktiven Autor, fiktiven Herausgeber und intendierten Leser miteinander und führt auf diese Weise eine Sprachgemeinschaft ein, die auf sprachlicher Gemeinsamkeit gründet und auf möglichst unbehindertes, direktes Kommunizieren und Verstehen abzielt. Hier wird eine Sprache gesucht, die alle miteinander verbindet und die nicht auf Repräsentation, sondern auf bestmöglichen Austausch unter allen gerichtet ist.

Zugleich wird ein (proto-)nationaler Raum auf der sprachlichen Ebene angedeutet und in die literarische Realität umgesetzt. Wird in der Vielfalt verwendeter Sprachen im Roman eine virtuelle Nation in ihren Umrissen skizziert, so kommt der hiervon unterschiedenen Sprachgemeinschaft von Autoren, Herausgebern und Lesern eine zentrale Rolle für die Kommunikation (und letztlich auch Führung) dieses bald schon nationalen Raumes zu. Gleichzeitig bildet diese Schicht nur den Kern einer möglichst breiten und in seiner Heterogenität der Erzählerfigur des Vorworts bewussten Lesergemeinde, welcher dieses Werk vielleicht nicht unmittelbar zugänglich, immerhin aber zugeeignet ist. Vom „gusto“ dieser Käuferschicht hängen „los autores, impresores, papeleros, comerciantes, encuadernadores y demás dependientes“, ${ }^{26}$ also der gesamte Literaturbetrieb, ab. All dies macht deutlich: Die Konturen eines neuen Literatursystems mit neuen Konsekrationsinstanzen, vor allem aber auch einer entsprechenden Leserschicht und Leserschaft, zeichnen sich ab. El Periquillo Sarniento belegt in seiner materiellen Existenz die Entstehung dieses neuen Raumes für das Schreiben, Publizieren und nicht zuletzt Lesen in einem Neuspanien, das sich auf dem Weg zum modernen Mexico befand.

Kommen wir nun aber zum internen paratextuellen Raum dieses Romans! In dem diesem ersten Vorwort unmittelbar folgenden „Prólogo de Periquillo Sarniento“ gelangen wir von der externen paratextuellen zur internen paratextuellen Ebene des umfangreichen Erzähltextes. Die im ursprünglichen Titel des Romans

25 Fernández de Lizardi, José Joaquín: El Periquillo Sarniento, S. 463.

26 Ebda., S. 4. 
angekündigte doppelte Kommunikationssituation wird hier insoweit eingelöst, als es nun die Figur Periquillo Sarnientos selbst ist, die sich zu Wort und an seine unmittelbaren und mittelbaren Leser wendet. Diese Kommunikationssituation ist selbst wiederum zweigeteilt, insoweit sie sich explizit auf zwei verschiedene Adressaten bezieht: Zum einen konstatieren wir die direkte Wendung des Vaters an seine Kinder, denen er gattungsgemäß allerlei Ratschläge, consejos und consejas, mit auf ihren Weg durch das Leben gibt. Zum anderen können wir die Anrede an eine Leserschaft beobachten, welche über diese erste Kommunikationssituation hinaus durch die Weitergabe des Manuskripts erreicht werden kann. Ist der externe paratextuelle Raum als „Schwelle“ (im Sinne Genettes ${ }^{27}$ ) zwischen textexternem und textinternem Bereich aufzufassen, so handelt es sich hier offenkundig um einen paratextuellen Raum, der unverkennbar textintern organisiert und Teil der Fiktion des Romans selbst ist. Wir überqueren gleichsam die Schwelle zum Roman, wobei auch hier die Leserpositionen von größter Relevanz für die Deutung des Gesamttextes sind.

Denn dies bedeutet nicht etwa, dass im Gegensatz zu Periquillo Sarniento die das erste Vorwort unterzeichnende Instanz („El Pensador“) eine reale textexterne Gestalt wäre. Auch sie ist nicht anders als der pícaro selbst eine vom realen Autor Fernández de Lizardi geschaffene literarische Figur, die wir in ihrer Artifizialität, in ihrem Geschaffensein, anerkennen und deuten müssen. Doch sind ihr textextern referentialisierbare Attribute beigestellt, welche diese Instanz des Vorworts zu einer für Paratexte typischen, zwischen textexternem und textinternem Bereich oszillierenden, im Text selbst angesiedelten Schwellenfigur machen. Mit dem realen Autor namens José Joaquín Fernández de Lizardi verwechseln dürfen wir auch sie nicht.

Unterscheiden wir um einer größeren Klarheit willen zwischen dem auf der Ebene der erzählten Zeit angesiedelten pícaro und dem auf der Ebene der Erzählzeit situierten, seinem Lebensende nahen Erzähler und belegen wir den ersteren mit seinem ihm zugelegten Spitznamen Periquillo Sarniento und den letzteren mit seinem am Anfang und Ende des Romans genannten ,bürgerlichen“ Namen Pedro Sarmiento! ${ }^{28}$ Bei einer derartigen Unterscheidung zeigt sich deutlich, dass die Instanz dieses zweiten Vorworts jene Erzählerfigur auf Ebene der

27 Genette, Gérard: Seuils. Paris: Seuil 1987.

28 Diese Trennung ließe sich in gewisser Weise mit jener zwischen Alonso Quijano und Don Quijote vergleichen. Zu den Beziehungen zwischen Fernández de Lizardi und Cervantes vgl. Lasarte, Pedro: Don Catrín, Don Quijote y la picaresca. In: Revista de Estudios Hispánicos (St. Louis) XXXIII, 3 (1989), S. 101-112; sowie González Cruz, Luis F.: El Quijote y Fernández de Lizardi: revisión de una influencia. In: Criado de Val, Manuel (Hg.): Cervantes: su obra y su mundo. Actas del I Congreso Internacional sobre Cervantes. Madrid: EDI 1981, S. 927-932. 
Erzählzeit ist, die uns aus der gattungstypischen rückschauenden Perspektive die Lebensgeschichte, seine Vida, präsentiert. Die unmittelbaren und ausdrücklich im Text genannten Adressaten (und damit der explizite Leser) dieses Lebensberichts sind die Kinder, für die allein kein Vorwort nötig gewesen wäre. Doch könnte diese Vida auch in andere Hände fallen; und so zeigt sich, dass gerade für diesen in seinen Grenzen unklar bleibenden Leserkreis eine paratextuelle Situierung (,una especie de Prólogo“) des nachfolgenden Textes vonnöten ist. Die bewusst offen gehaltene Leserschaft, die durch den nachfolgenden Bericht belehrt und unterhalten werden soll und in ihren Konturen die anonyme Leserschaft des ersten Vorworts intradiegetisch verlängert, wird mit der hintersinnigen Behauptung Pedro Sarmientos konfrontiert, dass nichts „ficción de mi fantasía“ sei und daher auch kein Grund bestehe, an „mi verdad“, an „meiner Wahrheit“, zu zweifeln. ${ }^{29}$

Damit aber wird die Leserschaft noch nicht in den ,eigentlichen' Text, in die Fiktion des Romans, entlassen. Vielmehr dient das zweite Vorwort als eine Art Schleuse zwischen externem und internem Paratext. Denn nun werden innerhalb des fiktionalen Raums des Romans „Advertencias generales a los lectores“ (Allgemeine Hinweise für die Leser) präsentiert, die die konkrete Textgestalt als Ergebnis der Arbeit eines kommentierenden, ergänzenden, streichenden, stilistisch umarbeitenden und den Text mit Anmerkungen versehenden Herausgebers darstellen. Wir haben es hier mit einer Herausgeberfiktion zu tun ...

Aus der Schwellenfigur des „Pensador“ ist damit ein intradiegetischer Editor geworden, der von Pedro Sarmiento unmittelbar vor den seinem Lebensbericht nachgestellten „Notas del Pensador“ als „un tal Lizardi“ (ein gewisser Lizardi) ${ }^{30}$ in den Romantext als Figur eingeführt wird. Auch diese Figur darf selbstverständlich nicht mit dem realen Autor gleichen Namens verwechselt werden, was innerhalb der Forschungsliteratur jedoch des Öfteren nicht berücksichtigt oder übersehen wurde. ${ }^{31}$ Wir wollen diese Figur ganz einfach „Lizardi“ nennen. Und wir beginnen zu begreifen, dass ein Jorge Luis Borges oder ein Italo Calvino, die ihre eigenen Autornamen in ihre Texte einfügten, selbstverständlich keineswegs die ersten waren, die sich derartiger Verwirrspiele bedienten, um die Selbstreflexivität ihres Schreibens als ästhetischen Mehrwert der Lektüre in Bewegung zu

29 Fernández de Lizardi, José Joaquín: El Periquillo Sarniento, S. 5.

30 Ebda., S. 453.

31 So findet sich selbst in der vergleichsweise differenzierten Studie Nancy Vogeleys die Behauptung, Fernández de Lizardi habe sich damit als Herausgeber selbst in den Text eingeführt (vgl. Defining the „Colonial Reader“, S. 793). Auch sie übersieht damit die für eine Analyse des Romans grundlegende Scheidung von textexternem und textinternem Bereich. 
setzen. Die fiktionale Erwähnung des eigenen Namens durch einen Schriftsteller besitzt eine lange literarische Tradition, sollte uns aber niemals dazu verführen, die textuell geschaffene Figur für den realen Autor zu halten.

Diese Instanz ist logischerweise befugt, Pedro Sarmiento als „nuestro autor“ (unseren Autor) $^{32} \mathrm{zu}$ bezeichnen und eine gewisse Problematisierung der moralisierenden Exkurse vorzunehmen, welche in der novela picaresca gattungsgemäß stets ein großes Gewicht besitzen. Die Erlaubnis für alle Eingriffe in den Text habe ihm der mit ihm freundschaftlich verbundene Autor selbst gegeben. Damit wird deutlich: Auf der Ebene der Fiktion ist „Lizardi“ der erste kritische Leser des Lebensberichts Pedro Sarmientos, dessen (Lebens-)Ende er selbst als intradiegetischer Augenzeuge miterlebt hat. Seine Arbeit und Aufgabe ist die eines zugleich Lesenden und Schreibenden, so dass sich die Leserschaft nun mit einer recht komplexen Modellierung von Stimmen konfrontiert sieht, die zu ihr sprechen: Pedro Sarmiento, der Verfasser des Lebensberichts, „Lizardi“ als dessen fiktiver Herausgeber und schließlich „El Pensador“ als um sein schriftstellerisches Überleben in der neuspanischen Gesellschaft ringender Autor. José Joaquín Fernández de Lizardi hat die paratextuelle Rahmung seines Romanerstlings reichhaltig gestaltet.

Denn selbstverständlich sind all diese Figuren das Werk des realen José Joaquín Fernández de Lizardi, der sie (so etwa auch die Leserfiguren) miteinander in Dialoge verwickelt und damit zu literarischem Leben erweckt. Wir dürfen feststellen, dass die Komplexität dieser Anlage sich mit so erfolgreichen Herausgeberfiktionen wie in Cervantes' Don Quijote oder Rousseaus Julie ou La Nouvelle Hélö̈se - wo die Briefe der Liebenden von einem literarisch eingeführten Herausgeber veröffentlicht werden - ohne weiteres messen kann. Der neuspanische Schriftsteller José Joaquín Fernández de Lizardi war, betrachten wir zunächst nur sein paratextuelles Werk, alles andere als ein bloßer literarischer Stümper: Er schrieb durchaus auf Augenhöhe mit der spezifisch spanischen literaturgeschichtlichen Tradition. Erlauben Sie mir an dieser Stelle ein Wort zur allgemeinen Situation! Die neuspanische Literatur, Philosophie oder Malerei, ja Kunst und Kultur insgesamt waren in Neuspanien um die Jahrhundertwende durchaus mit dem kulturellen Reichtum verschiedenster europäischer Länder vergleichbar. Das prachtvolle Museum von Carlos Slim in Mexico-Stadt kann mit seinen Schätzen hierfür den Beweis antreten.

Doch kehren zu unserem Gegenstand, Fernández de Lizardis El Periquillo Sarniento mit seiner Ausarbeitung von Lesen und verschiedener Leserfiguren, zurück! Ich kann an dieser Stelle nicht auf die Tatsache eingehen, dass ein länge-

32 Fernández de Lizardi, José Joaquín: El Periquillo Sarniento, S. 7. 
res Zitat aus dem Vorwort von Jamins 1776 in Paris erschienenem Le fruit de mes lectures - einem Werk, das Zitate griechischer und römischer Autoren enthält, von denen viele in El Periquillo Sarniento eingingen - die Kommunikationsstrukturen wie auch die Autorenposition in ihrer Komplexität noch zusätzlich bereicherte. Doch erweist sich bei der Untersuchung des paratextuellen Raums die im Bachtin'schen Sinne verstandene Vielstimmigkeit von Fernández de Lizardis Roman zunächst auch ohne Einbeziehung des spezifisch intertextuellen Raumes - gerade bei einem Romanerstling - als überaus beeindruckend.

Die auf der Ebene der fiktiven Herausgeberfigur „Lizardi“ angesiedelte Inszenierung der editorischen Tätigkeit in einem weiteren, zwischen erstem und zweitem Teil angesiedelten „Prólogo en traje de cuento“ (Prolog im Gewand einer Erzählung), stellt dies einmal mehr unter Beweis. So sehen wir nicht nur den Herausgeber zunächst alleine zu Hause bei der editorischen Arbeit, „con la pluma en la mano anotando los cuadernos de esta obrilla“, also mit der Feder in der Hand die verschiedenen Lieferungen dieses Werkes mit Kommentaren versehend..$^{33}$ Zugleich bemerken wir erneut, dass nach der Ansprache an den geneigten Herrn Leser, den „señor lector“, diese Kommunikationssituation von einem Dialog unterbrochen wird, in welchem sich der (fiktive) Herausgeber mit einem Freund namens „Conocimiento universal“ oder Universelle Erkenntnis über den bisherigen Erfolg des Periquillo Sarniento beim Lesepublikum unterhält. ${ }^{34}$ Es sind wiederum diese selbstreflexiven Textelemente, die uns mit Blick auf die Leserschaft interessieren.

Die Heterogenität des Lesepublikums - denn das Publikum sind alle und niemand, „el público es todos y ninguno“; es bestehe aus Gelehrten wie Dummköpfen, aus „sabios“ wie aus „necios“35 - wird dabei ebenso thematisiert wie erste, recht unterschiedliche Leserreaktionen auf die zuvor gelieferten und verkauften Kapitel des Romans. Deutlich wird dabei nicht nur, wie sich die einzelnen Figuren von den verschiedenen Kommunikationsebenen her dieselben Stichworte zuwerfen, deutlich wird auch, wie sehr die Selbstbezüglichkeit dieses Textes dessen unbestreitbare Modernität ausmacht.

Denn am Ende dieser Inszenierung der Herausgeberfigur verwandelt sich diese in eine Autorfigur, welche das als Erzählung verkleidete Vorwort zum zweiten Teil mit einer Wendung an den Leser abschließt und dergestalt die Feder des Herausgebers mit der Feder eines Autors und Schriftstellers vertauscht:

33 Fernández de Lizardi, José Joaquín: El Periquillo Sarniento, S. 187.

34 Ebda.

35 Ebda. 
Nein, mein Freund, diese Leute werden nicht gut von diesem Werke noch von dessen Autor in seinem Leben sprechen; aber verstehen Sie bitte, dass er von dieser Art von Rivalen größten Vorteil zieht, da - ohne daran zu denken - sie selbst es sind, welche das Werk von Ihnen beglaubigen und es sichtbar bezeugen, dass Sie in nichts von alledem, was Sie schreiben, lügen; und sagen Sie es nur, wie Ihr kleines Werk all jenes Gemurmel verachtet (denn als Kritiker kann man sie nicht und können sie sich nicht bezeichnen).

[...] Ich ergriff die Feder und schrieb unser Gespräch nieder, damit Sie, oh Freund und Leser, Geschmack daran finden und weiterlesen in der Geschichte des berühmten Periquillo. $^{36}$

Erneut haben wir es in dieser Passage mit einer in Szene gesetzten Dialogstruktur zu tun, welche den Autor mit einem Freund und Leser - und damit zugleich Schreiben und Lesen - in wechselseitige Spiegelungen einbindet und verwickelt. Der Leser sieht auf diese Weise zu bei der Entstehung des Textes, den er vor Augen hat, wird zum Augenzeugen der Entstehung jenes Romans, den er liest. Der distanzierte, anonyme Leser ist zu einem Freund geworden, der die Geschichte Periquillos lesend weiterverfolgen soll: Der „amigo lector“ ist der Käufer der nachfolgenden Kapitel und damit zu jener Figur avanciert, die das literarische Spiel überhaupt erst in Gang hält. Im Roman selbst ist er jedoch nur eine unter mehreren Leserfiguren, die von Fernández de Lizardi entworfen wurden. Er bildet - dies macht der Blick ins Atelier, in die Werkstatt deutlich - als Käufer einen notwendigen Bestandteil des textintern entworfenen Literaturbetriebs, der durch den Roman selbst evoziert wird.

Kommen wir nunmehr zum architextuellen, zum gattungsspezifischen Raum unseres neuspanischen Schelmenromans! Am Ende des fünfzehnten Kapitels des dritten und letzten Teils übergibt - wie bereits angedeutet wurde - der dem Tode nahe Pedro Sarmiento dem zu seinem Freunde gewordenen neuspanischen Journalisten Lizardi, der auch als Pensador Mexicano bezeichnet wird, zu treuen Händen das Manuskript seines Lebensberichts mit der Bitte, es zu bearbeiten und mit Anmerkungen zu versehen. Zuvor aber findet er noch Zeit und Gelegenheit, diesen Freund namens Lizardi zu porträtieren, einen „escritor desgraciado en vuestra patria y conocido del público“, ${ }^{37}$ einen unglücklichen und in unserem Vaterlande beim Lesepublikum bekannten Schriftsteller also. Dabei soll uns weniger dieses Selbstbildnis Fernández de Lizardis, das auch selbstkritische Züge enthält und den Roman gleichsam signiert, interessieren als jene kleine Bemerkung, die abschließend die Beziehung zwischen „Lizardi“ und Pedro Sarmiento

36 Ebda., S. 189.

37 Ebda., S. 453. 
erläutert: „So sehr haben wir uns geliebt, dass ich sagen kann, dass ich ein einziger bin mit dem Pensador und er mit mir“. ${ }^{38}$

Diese Bemerkung Pedro Sarmientos transgrediert offenkundig die Herausgeberfiktion und schließt unmittelbar an das Selbstbildnis die verschiedenen Ebenen des Schelmenromans autobiographisch kurz. Die in dieser wichtigen Passage behauptete Identität der beiden Romanfiguren wird noch dadurch verstärkt, dass „Lizardis“ erstes Wort dem kranken Freunde gilt: „Bis hierher schrieb mein guter Freund Pedro Sarmiento, den ich so sehr liebte wie mich selbst“. ${ }^{39}$ Damit nimmt „Lizardi“ nicht nur das Manuskript, sondern auch den Erzählfaden selbst in die eigenen schriftstellerischen Hände, was zum einen die Kontinuität des Erzählvorgangs sicherstellt, zum anderen die paratextuelle Rahmung des Gesamtwerks im nachhinein zusätzlich legitimiert und schließlich die romantechnischen Voraussetzungen dafür schafft, dass die Lebensgeschichte des Pedro Sarmiento von der Geburt bis zum Tode prinzipiell lückenlos dargestellt werden kann. So bietet der Roman seinen Leserinnen und Lesern - und dies ist keineswegs eine Marginalie - die Totalität eines gesamten Lebens.

Hieraus ergibt sich eine gewisse Transgression des architextuellen Grundschemas dieses Schelmenromans. El Periquillo Sarniento schreibt sich, wie wir sahen, von Beginn an in das Gattungsschema der novela picaresca, also des Schelmenromans, ein. $\mathrm{Zu}$ den gattungskonstitutiven erzähltechnischen Voraussetzungen hierfür zählt die Trennung zwischen einem erzählten und einem erzählenden Ich, wobei des ersteren Leben und Abenteuer in mehr oder minder chronologischer Abfolge aus der Perspektive eines zur Ruhe gekommenen, „reiferen“ oder „bekehrten“ Ich dargestellt werden. Dieses „reifere“ Ich, das erzählende Ich also, hat seinen Platz in der Gesellschaft (wenn auch nicht immer widerspruchslos und widerspruchsfrei) gefunden.

Die logische Konsequenz dieser strukturellen Anlage ist ein ständig kleiner werdender Abstand zwischen der Ebene der erzählten Zeit und jener der Erzählzeit, für El Periquillo Sarniento mithin die Spanne zwischen 1771 beziehungsweise 1773 (dem Zeitpunkt der Geburt) und 1813 (dem Jahr der Übergabe des Manuskripts und des Todes Don Pedros). Fallen beide Zeitebenen miteinander zusammen, so sind wir am Ende der histoire, also jener Summe chronologisch verfügbarer Erzählbausteine, die für die Anordnung durch eine Erzählerfigur bereitgestellt sind, angekommen. Nicht angekommen aber sind wir am eigentlichen Lebensende dieses Erzählers selbst, der von seinem eigenen Tod nur schwerlich berichten kann. Beispiele hierfür lassen sich sehr wohl aus anderen

38 Ebda., S. 454.

39 Ebda. 
Gattungen, meines Wissens aber nicht aus der Gattung des Schelmenromans selbst anführen.

Die strukturelle Anlage des Lazarillo de Tormes - eines gattungsbegründenden narrativen Textes, der sich ebenfalls als Vida präsentiert - legt als Ausgangsmodell späterer erzähltechnischer Variationen hiervon beredtes Zeugnis ab. Die im Periquillo Sarniento ebenfalls gattungskonform übernommene Trennung zwischen der Mobilität des erzählten Ich und der Statik des erzählenden Ich - eine Ökonomie, auf die noch zurückzukommen sein wird - bleibt ebenfalls bis zur Übergabe der Manuskriptseiten an den fiktiven Herausgeber namens „Lizardi“ gewahrt. Dieser Übergabe aber schließen sich gleichsam paratextuell die bereits erwähnten „Notas del Pensador“ sowie das sechzehnte und letzte Kapitel des Buches an, in welchem aus der Perspektive „Lizardis“ Tod und Bestattung des Pedro Sarmiento dargestellt werden.

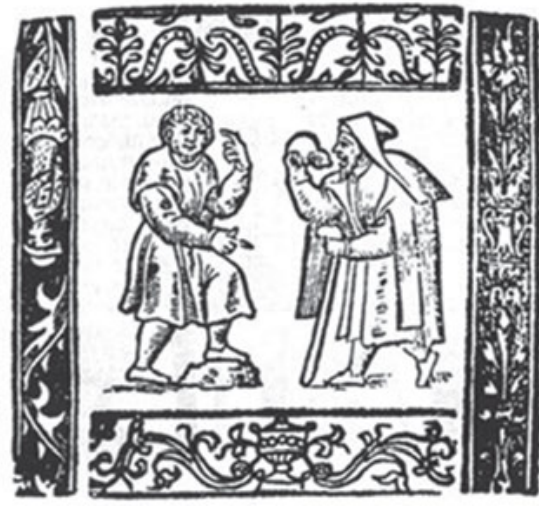

\section{of Le La vida oe Zazarillo oe zormes/ $y$ se fus fortungs: $y$ aduerfidades. Thueuanente impzeffe, corregida, y oe nueuo ańadis da eneftafegüdaim" preftion. -}

\section{Eendenfe en alcals oe benares,en carao salzedo Kibzero. zano DC. $\triangle B$. D. LIIII}

\author{
Abb. 90: Titelblatt einer der vier \\ Erstausgaben von La vida de Lázarillo de \\ Tormes, 1554.
}

Dabei handelt es sich um Ereignisse, die - so die Kapitelüberschrift - „llevan al lector por la mano al fin de esta ciertísima historia“, ${ }^{40}$ also den Leser an der

40 Fernández de Lizardi, José Joaquín: El Periquillo Sarniento, S. 460. 
Hand bis zum Ende dieser höchst gewissen Geschichte führen. Dieser literarische Kunstgriff erlaubt es, auf wenigen Seiten innerhalb des Romans nicht nur das Ineinanderfallen (wenn auch nicht die Fusion) von erzählter Zeit und Erzählzeit, von erzähltem Ich und erzählendem Ich, von Periquillo Sarniento und Pedro Sarmiento - und nicht umsonst sind beide Namen auf dem Grabstein verewigt vorzuführen. Er ermöglicht zugleich, das Gattungsschema des Schelmenromans, wie es der Lazarillo de Tormes vorgab, unter Rückgriff auf eine andere literarische Gattung zu erweitern, die den neuspanischen, vom Katholizismus geprägten Lesern zu Beginn des 19. Jahrhunderts wohlvertraut war: die Form der Heiligenviten. Denn diese stellten eine bei einer breiten Leserschaft wie auch bei einem des Lesens unkundigen Publikum eine höchst populäre literarische Erzählform dar, die sofort wiedererkannt wurde.

Die hagiographische Form erst ermöglicht den Zugriff auf ein gesamtes Leben von der Geburt bis zum Tode, einen Zugriff, der dem Menschen bezüglich seines eigenen Lebens verwehrt ist, sind dem individuellen Bewusstsein doch weder die eigene Geburt noch der eigene Tod zugänglich. Das ihm erreichbare Lebenswissen ist ebenso von seinem Anfang wie von seinem Ende her begrenzt. Die Literatur springt hier in die Bresche und ermöglicht die Verfügbarkeit eines gesamten Lebens von dessen Anfang bis zu dessen Ende, wobei der durch diese Verfügbarkeit (und Verfügungsgewalt) erzielte Lustgewinn bei hagiographischen Schreibformen gleichsam ideologisch bezahlt werden muss durch die Einreihung dieses individuellen Lebens in transzendente beziehungsweise heilsgeschichtliche Zusammenhänge. Denn die Leserschaft hat das Leben eines christlichen Heiligen vor Augen.

Was bedeutet dies für El Periquillo Sarniento? Pedro Sarmiento macht gegenüber seinen Söhnen sein eigenes Leben zum Exemplum, doch wird die Einordnung in ein transzendentes christlich-katholisches Schema erst dadurch gelingen, dass auch sein Sterben in seiner Sinnhaftigkeit dargestellt wird und so dem Leser als sinnhafte Einheit erscheinen kann. José Joaquín Fernández de Lizardi griff auf dieses Schema der exempelhaften Heiligenviten zurück, modifizierte aber dieses Grundschema nicht nur erzähltechnisch, indem er diese Rolle nicht einem extradiegetischen, sondern einem intradiegetischen Erzähler übertrug, sondern wandelte es auch ideologisch ab, indem er sein Bezugsmodell desakralisierte und nicht mehr in heilsgeschichtliche, sondern in weltlich-historische Zusammenhänge einband.

Auf diese Weise wird ein (erfundenes) Leben beispielhaft für eine Gesellschaft, deren Säkularisierung und Modernisierung fernab aller theologischen Prämissen eingefordert wird. Längst hat sich Neuspanien auf den Weg einer Nationenbildung, eines modernen nation building hin zum Nationalstaat Mexico, gemacht. Allein eine historische Rekontextualisierung, etwa hinsichtlich der revo- 
lutionären Ereignisse und Aufstände im gärenden Neuspanien, auf die der Roman explizit anspielt, ${ }^{41}$ konnte aber nicht genügen. Fernández de Lizardi musste daher eine weitere Gattungsform mit dem Grundmuster der novela picaresca verbinden und sein Gattungsschema für El Periquillo Sarniento entsprechend abändern.

Die Ersetzung heilsgeschichtlich-transzendenter Sinnangebote erforderte die zumindest perspektivisch angelegte Einbeziehung zukunftsbezogener Entwicklungsmodelle, die freilich erst in den letzten Teil des Romans, nachdem der pícaro die gesellschaftlichen Möglichkeiten des kolonialspanischen Herrschaftssystems erprobt und letztlich erfolglos ausgeschöpft hatte, eingeführt werden konnten. Als generisches Modell einer solchen kritisch auf die eigene Gegenwart gemünzten Zukunftsvision wählte der neuspanische Schriftsteller die Form der Utopie in ihrer ,klassischen' Ausprägung.

Er griff dabei auf Vorstellungen Platons und Aristoteles', auf Caussins La Cour sainte und Fénelons Télémaque, ${ }^{42}$ vor allem aber auf Thomas Morus' Utopia und damit auf ein Raummodell, nicht aber auf das Zeitmodell der Uchronie zurück, wie es Louis-Sébastien Mercier wenige Jahrzehnte zuvor in seinem L'An deux mille quatre cent quarante 1771 ins Werk gesetzt und damit die Form der modernen Zeit-Utopie wesentlich mitgeprägt hatte. ${ }^{43}$ Gleichviel, ob wir das 18 . Jahrhundert in Europa als das Goldene Zeitalter der Utopien oder als Krisenzeit der literarischen Utopie verstehen: Auffällig ist doch, dass sich der neuspanische beziehungsweise mexikanische Schriftsteller nur an der räumlichen, nicht aber an der zeitlichen Projektion und deren literarischer Filiation orientierte und dabei in starker Gattungskonformität all jene Elemente einblendete, die von Schiffbruch und Inselsituation über statische Stadt- und Gesellschaftsordnung bis hin

41 Nehmen wir den „Prólogo en traje de cuento“ ernst, so reicht die Romandiegese bis ins Jahr 1816, also dem sukzessiven Erscheinen der einzelnen Teile des Periquillo Sarniento.

42 Vgl. hierzu Hudde, Hinrich: Fernández de Lizardi. Literarische Utopie an der Schwelle der Unabhängigkeit Mexicos (mit Bemerkungen zu modernen lateinamerikanischen Utopien). In: Literaturwissenschaftliches Jahrbuch der Görres-Gesellschaft N.F. 27 (1986), S. 253-267, sowie speziell zu der grundlegende Vorstellungen Lizardis prägenden Beziehung zum Télémaque Strosetzki, Christoph: Fénelon et Fernández de Lizardi: De l'absolutisme au libéralisme. In: Oeuvres et Critiques (Tübingen) XIV, 2 (1989), S. 117-130.

43 Zweifellos ein wenig voreilig bezeichnete Raymond Trousson Mercier als „père de l’utopie moderne“; vgl. R.T.: Introduction. In: Mercier, Louis-Sébastien: L’An deux mille quatre cent quarante. Rêve s'il en fut jamais. Bordeaux: Editions Ducros 1971, S. 61. Eine nuanciertere und zugleich kritischere Sichtweise der Rolle Merciers geben Krauss, Henning: Der Ursprung des geschichtlichen Weltbildes, die Herausbildung der „opinion publique“ und die literarischen Uchronien. In: Romanistische Zeitschrift für Literaturgeschichte (Heidelberg) XI, 3-4 (1987), S. 337-352, sowie Kuon, Peter: Utopie et anthropologie au siècle des lumières ou: la crise d'un genre littéraire. In: Hudde, Hinrich / Kuon, Peter (Hg.): De l'Utopie à l'Uchronie. Formes, significations, fonctions. Actes du colloque d'Erlangen 16-18 octobre 1986. Tübingen: Gunter Narr Verlag 1988, S. 49-62. 
zu streng reglementierten Arbeits- und rigorosen Bestrafungsformen reichte und seinen eigenen utopischen Entwurf zu dem kanonischen Modell des Thomas Morus in enge Beziehung setzte. Fernández de Lizardi war, so dürfen wir kritisch anmerken, in diesem Bezug zur Utopia des Thomas Morus nicht ganz auf der literarisch-philosophischen Höhe seiner Zeit.

Doch wir müssen vorsichtig sein mit derartigen Einschätzungen der Romankunst des Neuspaniers! Denn all dies bedeutet keineswegs, dass es sich bei Fernández de Lizardis Entwurf um eine literarische „Imitation“ oder ein Plagiat handelte. Zum einen ist der Aufenthalt Periquillos auf der Insel Sancheofú die wohl erste literarische Utopie innerhalb der lateinamerikanischen Literaturgeschichte und daher per se eine epochemachende Innovation. Und zum anderen stellt die Projektion der Utopie von Hispanoamerika aus in den Osten auch insoweit eine grundlegende Neuerung, ja einen Bruch mit der europäischen Tradition dar, als nun nicht länger Amerika für die europäischen Autoren die leere Leinwand für deren eigene Projektionen abgab. ${ }^{44}$ Fernández de Lizardi betrat auf diesem Gebiet zweifellos literarisch-philosophisches Neuland.

Es gilt also, die Dinge im transatlantischen Spiel literarischer Relationen differenziert zu beurteilen. Die Entscheidung des neuspanischen Romanciers für die spezifisch utopische und damit gegen die noch junge uchronische Tradition, welcher ebenso literarhistorisch wie auch bezüglich der in ihr angelegten Historisierung politisch-gesellschaftlicher Gegenentwürfe eine hohe revolutionäre Potenz zukam, darf nicht aus heutiger Perspektive als ideologisch rückschrittlich missdeutet werden, weil sie sich etwa an einem statischen Geschichtsbild orientiert hätte. Gewiss ist nicht von der Hand zu weisen, dass eine statische Vision der Geschichte, wie sie sich innerhalb der an die Utopia von 1516 anschließenden Tradition oftmals beobachten lässt, auch dem Utopie-Kapitel des Periquillo Sarniento nicht fremd ist. Doch dürfen wir diese ästhetisch meiner Ansicht nach überzeugende Lösung nicht als ein Zeichen für eine wie auch immer geartete rückwärtsgewandte ideologische Orientierung des mexikanischen Autors deuten, sondern müssen begreifen, welche Erkenntnispotentiale der paradox auf den Raum bezogenen U-topie innerhalb des gesellschaftlichen Projekts Fernández de Lizardis zukamen. Hierzu gilt es, die topographische Dimension des von Fernández de Lizardi in seinem Roman ausgespannten nationalen Raums genauer zu erfassen.

44 Vgl. hierzu Cerutti Guldberg, Horacio: Utopía y América latina. In (ders.): Presagio y tópica del descubrimiento. México: CCYDEL 1991, S. 21-33. Dabei erstaunt, dass in dieser in Mexico vorgelegten Arbeit der utopische Entwurf von Fernández de Lizardi unerwähnt bleibt. 
Zuvor aber sollten wir in der gebotenen Kürze unsere Analyse des architextuellen Raumes von El Periquillo Sarniento abschließen. Dabei stoßen wir zunächst auf die in den Text integrierten lyrischen Formen, die zumeist intradiegetisch verankert sind und von der Fernández de Lizardi gewidmeten Forschung kaum einmal beachtet wurden. Paradigmatisch hierfür scheinen mir jene décimas zu sein, die Periquillo unmittelbar nach einem gescheiterten Selbstmordversuch wie in einem Spiegel aus Tinte niederschreibt. Er hatte sich nach seiner glücklichen Rückkehr von der utopischen Insel nach Mexico einmal mehr Lebensformen des Adels und damit nicht dem bürgerlichen Wert der Arbeit verpflichtet gefühlt, war aber bald schon in die urbane Halbwelt abgestiegen und hätte sich nach schmachvollen Erlebnissen selbst ins Jenseits befördert, wäre das von ihm gewählte Verfahren der Selbsttötung nicht zu umständlich und ungeschickt gewesen.

So aber gelangt er nun zur lyrischen Erkenntnis des „Du musst Dein Leben ändern“, eine geradezu in der von Rainer Maria Rilke gefundenen Formel modellierte Bewusstwerdung, die nachhaltig nur in der verdichteten Form der Lyrik erfolgen zu können scheint und nicht von ungefähr zugleich die Züge des Lehrgedichts trägt:

Aprended, hombres, de mí, lo que va de ayer a hoy; que ayer conde y virrey fui y hoy ni petatero soy.

Ninguno viva engañado creyendo que la fortuna si es próspera, ha de ser una sin volver su rostro airado. Vivan todos con cuidado cada uno mire por sí, que es la suerte baladí, y se muda a cada instante: yo soy un ejemplo andante: Aprended, hombres, de mí.

Muy bien sé que son quimeras las fortunas fabulosas, pero hay épocas dichosas, y llámense como quiera. Si yo aprovechar supiera una de éstas, cierto estoy que no fuera como voy; pero desprecié la dicha, y ahora me miro en desdicha: ¡lo que va de ayer a hoy! 


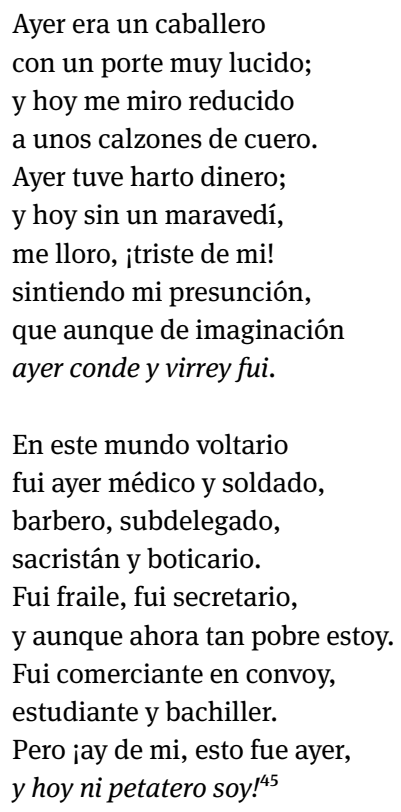

Zweifellos stehen wir hier vor einer verdichteten Zusammenfassung aller Ups und Downs im Leben eines picaro und zugleich vor der Formulierung eines Lebenswissens, das im Schelmenroman vom ,reifen', am Ende seines Lebens stehenden erzählenden Ich an seine Leserschaft weitergegeben werden soll. Wir sehen in diesem Gedicht die Funktion der Lebensberatung und den picaro als Ratgeber für das Leben der Leserinnen und Leser. So ist dieses Lehrgedicht im Zeichen eines akkumulierten Lebenswissens vor allem auch ein Lebensgedicht und greift all die Gattungen wieder auf, in denen aus exemplarischer Sicht die Exempla eines Lebens der Leserschaft vor Augen geführt wurden: als Abschreckung oder - häufiger - als Modell eines insbesondere christlichen Lebens. Die Ratgeberfunktion, die gesellschaftliche Funktion der Lektüre ist in Fernández de Lizardis Romanerstling - und darüber hinaus auch in Lateinamerikas Romanerstling - omnipräsent. Ohne all jene Konfigurationen im Bereich von Schreiben, Publizieren, Distribuieren und vor allem Lesen, die wir im Umfeld von José Joaquín Fernández de Lizardis Meisterwerk beobachten können, wäre der Aufstieg des lateinamerikanischen Romans etwas mehr als hundert Jahre später nicht vorstellbar gewesen.

45 Fernández de Lizardi, José Joaquín: El Periquillo Sarniento, S. 401. Auf eine Übersetzung wurde an dieser Stelle ausnahmsweise verzichtet. 
An diesem noch von Periquillo und noch nicht von Pedro Sarmiento niedergeschriebenen Gedicht interessiert uns nicht die intertextuell bemerkenswerte Tatsache, dass es sich um eine freie Anverwandlung von Versen Góngoras handelt, auf die bereits Lope de Vega zurückgegriffen hatte. Auch mag für die Fragestellung der gesamten Vorlesung die architextuell sicherlich signifikante Erkenntnis nur nachgeordnete Bedeutung besitzen, dass sich an dieser Passage zeigt, dass die Gattung des Romans auch in Hispanoamerika von Beginn an fähig war, andere Gattungen in sich aufzunehmen und auf diese Weise andere literarische Traditionsstränge sich anzueignen. Der Roman ist folglich nicht nur in Europa, sondern auch in den Amerikas ein kannibalistisches, gattungsvertilgendes Genre.

Für die Ziele unserer Vorlesung bedeutungsvoller scheint mir, dass in diesem Lehrgedicht, dessen wiederkehrender Vers Aprended, hombres, de mí das eigentliche didaktische Leitmotiv des Romans beziehungsweise des Lebensberichts Don Pedros sein könnte, die Grundelemente der histoire dem Leser wie dem Schreibenden selbst kopräsent vor Augen geführt und wie in einem gewaltigen textuellen Brennspiegel fokalisiert werden. Dieser Verdichtungsprozess der lyrischen Form allein führt noch nicht zur rettenden Wende, verweist aber auf ein geschärftes Bewusstsein des Protagonisten, das eine unabdingbare Voraussetzung für die den Lebensbericht abschließende conversión, seinen ehrsamen Sinneswandel, ist. Zugleich markiert dieses wie auch die anderen in Periquillo Sarniento abgedruckten Gedichte einen Ruhepunkt innerhalb der Bewegungen des Textes wie des Lesers. Die bei einem Gedicht stets herabgesetzte Geschwindigkeit der Lektüre verleiht dem Leseprozess in gewisser Weise eine Atempause: Die Schnelligkeit der Textlektüre bei einem Erzähltext wird durch die Gedichte gedrosselt und so recht wirkungsvoll rhythmisiert.

Weitere in den Roman integrierte Gattungen, die innerhalb des gesamten Textes eine wesentlich größere Ausdehnung erreichen, betreffen nicht-fiktionale, nicht-narrative Schreib- und Ausdrucksformen, von denen insbesondere wissenschaftliche Abhandlung, theologisches Traktat, Predigt und Essay als besonders relevant zu nennen sind. Sie stehen zum narrativen Text in einem eigenartigen Spannungsverhältnis, das bereits in den „Advertencias generales a los lectores“ thematisiert wurde, nachfolgenden Leserinnen und Lesern aber bis heute die größten Schwierigkeiten bei der Lektüre zu machen scheint. Diese Schreibformen bilden das Gros der sogenannten „Digressionen“ und „moralisierenden Abschweifungen“, die Fernández de Lizardis Roman immer wieder zum Vorwurf gemacht wurden. Das Spannungsverhältnis zwischen dominant fiktionalen und nicht-fiktionalen Teilen des Romans soll uns am Ende unserer Analyse des Periquillo Sarniento beschäftigen. 
Bereits jetzt aber dürfen wir festhalten, dass der hier aufgezeigte Einbau der unterschiedlichsten Gattungen und Schreibformen Fernández de Lizardis Roman eine überaus heterogene, ja disparate Textur vermittelt, die dank der ungeheuren Flexibilität und Integrationsfähigkeit der als generatives Grundmuster dienenden novela picaresca ausgebildet werden konnte. Der Schelmenroman ist ein heterogenes und zugleich flexibles Genre, das nicht ohne Grund sich über Jahrhunderte quer durch die Geschichte des Romans in den Literaturen der Welt erhält. Der architextuelle Raum des Periquillo Sarniento weist dabei eine für den spanischsprachigen Schelmenroman so ungewöhnliche Heterogenität auf, dass deren Ursachen in den Spezifika eines in Amerika angesiedelten Schreibens aufgesucht werden müssen.

Vergessen sollten wir darüber nicht, dass es José Joaquín Fernández de Lizardi in seinem Periquillo Sarniento gelang, mit lyrischen und essayistischen Formen just jene Gattungen in den Roman zu integrieren, denen Angel Rama eine gewisse epistemologische Priorität innerhalb der hispanoamerikanischen Literaturen einräumte. Für den Kontext unserer Vorlesung - und daher fallen auch die meisten nachfolgenden Analyseteile einer bereits veröffentlichten Untersuchung $^{46}$ zu diesem Thema weg - ist es jedoch entscheidend, dass der Aufbau unterschiedlichster Räume im Roman sich stets am Vorhandensein oder der künftigen Schaffung eines Lesepublikums in Neuspanien orientiert.

Dass Fernández de Lizardi selbst seinen Roman durchaus als Einheit betrachtete, mag schon aus der Tatsache hervorgehen, dass an verschiedenen Stellen dieses Erzähltextes auf eine wechselseitig sich verstärkende Wirkung seiner heterogenen Ingredienzien aufmerksam gemacht wurde. So lesen wir im vierzehnten Kapitel des ersten Teils des Periquillo Sarniento:

Das gute Beispiel bewegt weit mehr als die Ratschläge, die Insinuierungen, die Predigten und die Bücher. All dies ist gut, aber letztendlich sind es Worte, die fast immer vom Wind fortgetragen werden. Die Lehre, welche durch die Augen eintritt, drückt sich stärker ein als jene, die uns durch den Hörsinn erreicht. ${ }^{47}$

Die Gegenüberstellung der Sinnesorgane des Gesichts- und des Hörsinnes zur Aufnahme der doctrina, der guten Lehre, und deren Anordnung in einer Hierarchie überrascht in dieser Passage durchaus. Doch wenige Zeilen vor dem Ende des letzten Romankapitels, in welchem erneut in Form eines Dialogs zwischen

46 Vgl. Ette, Ottmar: Fernández de Lizardi: „El Periquillo Sarniento“. Dialogisches Schreiben im Spannungsfeld Europa - Lateinamerika. In: Romanistische Zeitschrift für Literaturgeschichte / Cahiers d'Histoire des Littératures Romanes (Heidelberg) XXII, 1-2 (1998), S. 205-237.

47 Fernández de Lizardi, José Joaquín: El Periquillo Sarniento, S. 113. 
dem fiktiven Herausgeber und der Witwe Pedro Sarmientos, der Inhaberin der Autorenrechte ihres Mannes also, auf die Nützlichkeit des Buches für das Lesepublikum hingewiesen wird, treffen wir erneut auf die Spezifik von Auge und Ohr. Denn der Herausgeber namens „Lizardi“ begründet seine Hochschätzung des Lebensberichts seines Freundes wie folgt:

Die moralhaltigen Bücher belehren, dies ist richtig, doch tun sie dies nur durch die Ohren; und eben darum vergisst man ihre Lektionen leicht wieder. Werke wie das vorliegende aber instruieren durch die Ohren und zugleich durch die Augen. [...] Wenn wir von diesen Tatsachen lesen, so scheint es uns, als ob wir sie anschauen würden, und so behalten wir sie im Gedächtnis [...]. ${ }^{48}$

Wir können daraus auf die dem Schreiben zugrunde liegende Theorie der Wirkkraft von Lektüre bei Fernández de Lizardi schließen. Ziel eines auf Wirkung berechneten Schreibens ist es demnach, Hörsinn und Gesichtssinn, Augen und Ohren der Leserschaft gleichermaßen anzusprechen und für das Gedächtnis zu aktivieren. Aufgabe eines solchen Buches wie des Periquillo Sarniento ist es folglich, mehr zu sein als nur einfach Buch; es gilt, das eigene Medium der bloßen Worte gleichsam transmedial zu überschreiten.

Zugleich ergibt sich eine Auffassung, die durchaus kongruent ist mit den gattungsspezifischen Schwerpunkten des traditionellen Schelmenromans. Denn nicht nur die consejos, sondern - so dürfen wir ergänzen - auch deren Zusammenspiel mit den consejas steht im Zentrum der Aufgabe und der Arbeit des Schreibenden. Diese ,Arbeit‘, so erfahren wir nun, besteht in ganz wesentlicher Weise darin, nicht nur ein bestimmtes Lesepublikum an die Literatur heran-, sondern diesem Publikum auch Exempla vor Augen zu führen und sich ihm buchstäblich einzuprägen. Das Ohr, bekanntermaßen das Organ des wahren Christen und des rechten Glaubens, vertraut allein dem Medium der Luft, dem Wind, der die Worte der Predigt mit sich trägt. Das Auge dagegen wird durch Lebensbilder angesprochen, die im Gedächtnis festgehalten werden können oder sich, wie es in dieser Passage heißt, dem Gedächtnis einprägen (imprime).

Gestatten wir uns hier einen kurzen Seitenblick auf die weitere Geschichte der lateinamerikanischen Literaturen! Denn nicht anders hatte Próspero in José Enrique Rodós kurz vor der Wende zum 20. Jahrhundert in Montevideo verfassten Erfolgsschrift Ariel am Ende des Jahrhunderts von seinen Schülern gefordert, sich das Bild des von ihm beschworenen Luftgeistes einzuprägen: „Ich will, dass das leichte und anmutige Bild dieser Bronze sich von nun an dem sichersten Orte im Inneren Eures Geistes einprägt.“ (,Yo quiero que la imagen leve y graciosa de

48 Ebd., S. $463 f$. 
este bronce se imprima desde ahora en la más segura intimidad de vuestro espíritu." $)^{49}$ Diese Einprägung, diese Prägekraft hat ohne jeden Zweifel etwas Autoritäres, Aufdrückendes, ja Gewalttätiges!

Die Bedeutung, die im Periquillo Sarniento dem Auge für die Kraft der Memorisierung beigemessen wird, steht dabei zweifellos mit jener Dominanz des Auges in Verbindung, die sich seit dem Übergang vom 18. zum 19. Jahrhundert im Bereich der epistemologischen Grundlagen menschlicher Erfahrung nachweisen lässt. ${ }^{50}$ Nicht Auge oder Ohr, nicht consejas oder consejos, nicht Fiktion oder Diktion, sondern jeweils beides zusammen soll auf das zu bildende Lesepublikum im noch protonationalen Neuspanien einwirken. Dabei gilt es im Kontext unserer Vorlesung zu berücksichtigen, dass wir uns zu diesem Zeitpunkt in der Tat noch in einer Übergangsphase zwischen dem lauten und dem stillen Lesen befinden, dass also in der Tat - auch im Kontext von Lesergruppen, denen dieser Text vorgelesen wird - ein Miteinander und Ineinander beider Formen des Lesens besteht, die uns heute eher fremd geworden sind. Wir verstehen so hinsichtlich der angesprochenen Sinne besser, worum es Fernández de Lizardi in seiner Findung und Erfindung eines Lesepublikums ging.

Dies führt uns zur Problematik der unterschiedlichen Leserfiguren im Romantext zurück. Wir können uns dieser Fragestellung nach dem Lesepublikum nun aus einer neuen Perspektive nähern, indem wir die Bewegungen des pícaro auf der Ebene der erzählten Zeit, also zwischen seiner Geburt um 1771 und seinem Tod im Jahre 1813, als Bewegungen eines Verstehens nachvollziehen und analysieren. Dabei ist es möglich, die Deplatzierungen des Protagonisten in El Periquillo Sarniento in Beziehung zu setzen zu verschiedenen Bewegungs- und Verstehensmodellen, von denen sich mindestens fünf verschiedene Grundfiguren unterscheiden lassen: Erstens eine kreisförmige Reisebewegung, die den Reisenden wieder an seinen Ausgangsort zurückführt; zweitens ein Pendeln des Reisenden zwischen zwei oder mehreren Orten; drittens eine lineare Bewegung von einem Ausgangs- zu einem Zielpunkt; viertens eine stern-

49 Rodó, José Enrique: Ariel. Edición de Belén Castro Morales. Madrid: Anaya \& Mario Muchnik 1995, S. 96f. Ich benutze die deutschsprachige Ausgabe von Rodó, José Enrique: Ariel. Übersetzt, herausgegeben und erläutert von Ottmar Ette. Mainz: Dieterich'sche Verlagsbuchhandlung 1994, S. 186.

50 Vgl. hierzu Ette, Ottmar: Diderot et Raynal: l'oeil, l'oreille et le lieu de l'écriture dans l',Histoire des deux Indes“. In: Lüsebrink, Hans-Jürgen / Strugnell, Anthony (Hg.): L',Histoire des deux Indes": réécriture et polygraphie. Oxford: Voltaire Foundation 1996, S. 385-407, sowie La mise en scène de la table de travail: poétologie et épistémologie immanentes chez Guillaume-Thomas Raynal et Alexander von Humboldt. In: Wagner, Peter (Hg.): Icons - Texts Iconotexts. Essays on Ekphrasis and Intermediality. Berlin - New York: Walter de Gruyter 1996, S. 175-209. 
förmige Bewegung, die den Reisenden immer wieder zu seinem Ausgangspunkt zurück und von diesem ausgehend wieder zu neuen Bewegungen führt; und schließlich fünftens die Grundfigur einer Reise, die weder über einen konkreten Ausgangspunkt noch über einen konkreten Zielpunkt verfügt und sich dem Spiel des Zufalls öffnet. ${ }^{51}$

Versuchen wir, diese fünf Grundfiguren von Verstehensbewegungen im Raum auf Fernández de Lizardis Roman zu beziehen, so bemerken wir bald, dass im Periquillo Sarniento verschiedene Grundfiguren miteinander klug kombiniert wurden. Zwar ist der Reiseweg des neuspanischen pícaro vergleichbar mit seinen spanischen Vorgängern in grundlegender Weise vom Zufall und den zufälligen Bekanntschaften im Verlaufe dieses Weges bestimmt, doch ist für die gesamte Struktur des Romans eine eher sternförmige Konfiguration und Anlage festzustellen, die sehr wohl von den spanischen Vorbildern abweicht. Wenn wir in den gesamten Reiseverlauf eingebettete kreisförmige Reisestrukturen wie etwa die Reise auf die Philippinen mit Hinweg und Rückweg über Acapulco außer Betracht lassen, können wir die Bewegungen des pícaro zwar in gewisser Weise einem itinerarischen Schema zuordnen, das von Digressionen und Exkursionen unterbrochen wird. Doch dominiert über den gesamten Romanverlauf zweifellos eine Kombination der soeben genannten vierten und fünften Grundfigur, so dass wir von einer mehr oder minder vom Zufall bestimmten, aber stets am Zentrum der Hauptstadt Mexico sternförmig orientierten zentripetalen Verstehensbewegung sprechen dürfen. Damit zeigt sich nicht nur die Aufhebung einer offenen in einer geschlossenen Form, sondern zugleich auch die Ausrichtung einer weiten Landfläche an einem zentralen Ort, der Hauptstadt des Vizekönigreichs Neuspanien. Es macht sich von Beginn an eine grundlegende Veränderung des neuspanischen Romans gegenüber seinen spanischen Vorbildern und Modellen bemerkbar, eine Veränderung, die mit dem transatlantischen Übersetzungsprozess der novela picaresca nach Neuspanien zu tun hat.

Die Abweichung Periquillo Sarnientos vom gattungskonformen Bewegungsschema des spanischen Schelmenromans ist insoweit signifikant, als sich hier allen Zufällen zum Trotz eine zentralisierte Bewegung durchzupausen vermag, die mit den politischen Zuständen im Vizekönigreich, aber auch mit der Zentralisierung des künftigen mexikanischen Nationalstaats in Beziehung gesetzt werden darf, aller Auseinandersetzungen zum Trotz, die sich im gerade unab-

51 Vgl. zur Unterscheidung sowie Analyse dieser und anderer Bewegungsfiguren Ette, Ottmar: ReiseSchreiben. Potsdamer Vorlesungen zur Reiseliteratur. Berlin - Boston: Walter de Gruyter 2020. 
hängig gewordenen Staatsgebilde die Anhänger föderativer und zentralstaatlicher Strukturen lieferten. Zugleich erlaubt es die Sternfigur, auch auf der Ebene der erzählten Zeit selbst jenen für die Ökonomie des Schelmenromans grundlegenden Wechsel zwischen Bewegung und Ruhe einzuführen, der die literarische Modellierung bestimmter Umbrüche erlaubt.

Begreifen wir die (Reise-)Bewegungen des pícaro im Raum als Verstehensprozesse, die vom Lesepublikum nachvollzogen werden sollen, dann überrascht es nicht, dass die Modellierung bestimmter Orte, an denen sich wichtige Veränderungen ergeben, topisch akzentuiert werden muss. Diese Orte des Wandels und der Bewusstwerdung aber werden nicht wie an anderen Stellen nur durch diskursive Passagen, sondern vor allem durch verortete Gedichte bezeichnet. Es handelt sich dabei um lyrische Ausdrucksformen einer individuellen Bewusstwerdung, die bestimmten Orten innerhalb der hermeneutischen Bewegungsabläufe zugeordnet werden können.

Die in den Romanablauf integrierten Gedichte punktieren und rhythmisieren die hermeneutischen Bewegungen des romaninternen Protagonisten wie der romanexternen Leserschaft. Das durch den Gattungswechsel notwendige Innehalten dieses Lesepublikums an bestimmten Orten des vom pícaro durchlaufenen Reiseweges führt dabei zu einer Spatialisierung der Verstehensprozesse und damit zu einer effektiven, augenfälligen Übertragung der hermeneutischen Bewegung auf die Rezipienten. Wendepunkte des Lebensweges werden auf diese Weise semantisch aufgeladen und der Leserschaft plastisch vor Augen geführt. Leben und Lesen werden miteinander korreliert.

Die von einem aktiven Lesepublikum nachzuvollziehende hermeneutische Bewegung ist an den nationalen, an der Hauptstadt Mexico ausgerichteten territorialen Raum gekoppelt. Ist, wie Dieter Janik ${ }^{52}$ nachwies, der Begriff der sociedad in Fernández de Lizardis Gesamtwerk bereits am modernen Gesellschaftsbegriff Rousseau'scher Provenienz orientiert und bildet die in Szene gesetzte Vorstellung einer patriarchalisch am Vater ausgerichteten Familienstruktur in nuce die grundlegende Sozialstruktur ab, dann lässt sich ein erst noch zu schaffendes nationales Lesepublikum, das die Arbeit des Schriftstellers honoriert und den Einfluss des escritor público auf die Formierung der neuen Gesellschaft stärkt, als die grundlegende Vermittlungsebene zwischen einem modern konzipierten Gesellschaftsbegriff und einer neu definierten Rolle des Schriftstellers innerhalb dieser Gesellschaft verstehen. Diese Konstellation ist von fundamentaler Wichtig-

52 Janik, Dieter: „El Periquillo Sarniento“ de J.J. Fernández de Lizardi: una normativa vacilante (sociedad - naturaleza y religión - razón). In: Ibero-Amerikanisches Archiv (Berlin) XIII, 1 (1987), S. 49-60. 
keit für die weitere Entwicklung des Romans in den lateinamerikanischen Literaturen des 19. und vor allem des 20. Jahrhunderts.

Innerhalb dieser Gemeinschaft der Lesenden kommt dem Schriftsteller neuen Typs - des Typus einer Moderne, welche sich in den spanischen Kolonien Amerikas nicht zuletzt in der Independencia Gehör verschaffen sollte - eine zentrale und als patriarchalisch $\mathrm{zu}$ bezeichnende intellektuelle Leitfunktion $\mathrm{zu}$. Es ist daher nicht nur die Kommunikationssituation zwischen einem Vater und seinen Kindern, sondern mehr noch jene zwischen einem von Mäzenen unabhängigen Schriftsteller und seinem sich formierenden Lesepublikum, das die Grundstrukturen einer künftigen neuen Gemeinschaft und Gesellschaft vorwegnimmt. Hieraus erklärt sich das ganze Gewicht, das dem paratextuellen in seiner Verbindung zum nationalen Raum zukommt.

Ist die Beziehung zwischen Literatur und Nation im hispanoamerikanischen Roman der Romantik über die (zumeist missglückende) Liebesgeschichte - wie wir noch sehen werden - in Form einer nationalen Allegorese vermittelt, geschieht dies 1816 im Periquillo Sarniento über die erst noch zu definierende Beziehung zwischen einem sich am Literaturmarkt orientierenden Schriftsteller neuen Typs und einem nationalen beziehungsweise protonationalen Lesepublikum, das es trotz seiner sozialen, rassischen und kulturellen Heterogenität als potentielle Käuferschicht anzusprechen und zu gewinnen galt. Fernández de Lizardis erklärtes Ziel war es, einer in Amerika geschriebenen Literatur, welcher der Zugang zum Lesepublikum in Spanien noch ein knappes Jahrhundert lang, bis zu den Erfolgen der modernistas, verwehrt bleiben sollte, ein eigenes Publikum zu finden und zu erfinden.

El Periquillo Sarniento bezeichnet diesen für die weitere Entwicklung der lateinamerikanischen Literaturen entscheidenden Augenblick und erklärt ihn zum Ausgangspunkt der literarischen Kreation weit über José Joaquín Fernández de Lizardi hinaus. Die Konstruktion des Nationalen als (prä)nationaler Kommunikationsraum - und nicht so sehr die Kontingenz der Jahreszahlen - macht den ersten Roman des „Pensador Mexicano“ zu einem wahrhaften und wirkungsvollen Gründungstext der hispanoamerikanischen Literaturen. Er bildet gleichsam die Basis für jene anhebende Romanproduktion, welche im weiteren Verlauf des 19. Jahrhunderts in Lateinamerika auf grundlegende Weise das Schreiben wie das Lesen ins Zeichen der umkämpften Nation stellen wird. Dass dabei der Liebe und den verbotenen Liebeskonstellationen eine zentrale, da eminent politische Rolle zukommen sollte, wird uns an dieser Stelle unserer Vorlesung nicht überraschen, sind wir doch mittlerweile bestens vertraut mit den politischen Implikationen der Liebe in den Zeiten der Cholera - um Gabriel García Márquez’ Romantitel zu zitieren, mit dem wir uns noch beschäftigen werden -, ich meine in den Zeiten politischer Umwälzungen, wie sie die lateinamerikanischen Gesellschaften im 
weiteren Verlauf des 19. Jahrhunderts prägten. Der schillernden, facettenreichen und widerspruchsvollen Brillanz dieser Liebesgeschichten im hispanoamerikanischen Roman der Romantik wollen wir in der Folge unsere ganze Aufmerksamkeit widmen! 